\title{
A demand response-centred approach to the long-term equipment capacity planning of grid-independent micro-grids optimized by the moth-flame optimization algorithm
}

\author{
Soheil Mohseni*, Alan C. Brent, Daniel Burmester \\ Sustainable Energy Systems, School of Engineering and Computer Science, Faculty of Engineering, \\ Victoria University of Wellington, PO Box 600, Wellington 6140, New Zealand \\ *Corresponding author, Email: soheil.mohseni@ecs.vuw.ac.nz
}

\begin{abstract}
The off-grid electrification of remote communities by utilizing renewable energy technologies through the development of smart micro-grids is necessary to realize the sustainable development goals. Optimal sizing of an isolated micro-grid is challenging as it needs to satisfy the electricity demand of the customers from a long-term perspective, whilst adhering to constraints in terms of power supply reliability and system operation without losing computational tractability. This paper proposes a novel method for the optimal sizing process, subject to satisfying a reliability index for meeting the loads. The proposed method also incorporates a direct load control demand response program, and utilizes a data compression-based model reduction technique to flatten the load curve and reduce the computational effort. Furthermore, a conceptual micro-grid model incorporating photovoltaic panels, wind turbines, a battery bank, a DC/AC converter, and an electric vehicle parking lot is used as a test-case system to evaluate the performance of the proposed optimal sizing method. Moreover, a maiden attempt is made to investigate and confirm the effective application of the moth-flame optimization algorithm (MFOA) within the context of the proposed methodology. Accordingly, the performance of the MFOA is compared with the most preferred and up-todate meta-heuristics employed for solving the optimal equipment capacity planning problems of renewable and sustainable energy systems, which has confirmed its superiority in terms of nearing the optimal solutions. In addition, the simulation results demonstrate that implementing a demand response program, by scheduling the charging of electric vehicles, together with directly controlling the domestic deferrable loads, can avoid overloading. This improves the utilization of the available components, which, in turn, reduces the size of some of the components and the life-cycle cost of the system. Moreover, Hengam Island, Iran is used as a representative case study site to demonstrate the applicability and effectiveness of both the proposed method and the conceptualized micro-grid system: the calculated levelized cost of electricity of $\$ 0.15 / \mathrm{kWh}$, the discounted payback period of 10.53 years, the profitability index of $2.09 \%$, and the internal rate of return of $11.28 \%$, offer incontrovertible proof that the realization of the conceptualized micro-grid on this island is not only technically feasible, but also economically viable.
\end{abstract}

Keywords: Micro-grid; Renewable energy sources; Optimal sizing; Demand response; Meta-heuristic optimization; Electric vehicle

\begin{tabular}{|lll|}
\hline $\begin{array}{l}\text { Nomenclature } \\
\text { Acronyms }\end{array}$ & $E L F_{\text {load }}, E L F_{l o t}$ & $\begin{array}{l}\text { ELF indices for evaluating the } \\
\text { reliability of supplying the } \\
\text { residential and EV charging loads } \\
\text { penalty factors used to convert the } \\
\text { reliability indices to infinite costs }\end{array}$ \\
\hline
\end{tabular}




\begin{tabular}{|c|c|c|c|}
\hline $\mathrm{ACO}$ & ant colony optimization & pen $_{\text {bat }}$ & $\begin{array}{l}\text { penalty factor used to maintain the } \\
\text { final battery energy level below its } \\
\text { initial value }\end{array}$ \\
\hline DERs & distributed energy resources & ir & interest rate $[\%]$ \\
\hline DLC & direct load control & $n$ & total number of operating hours \\
\hline DPP & dynamic payback period & $d$ & $\begin{array}{l}\text { dimension of the problem, i.e. the } \\
\text { number of decision variables }\end{array}$ \\
\hline DR & demand response & $k$ & maximum number of moths \\
\hline DSM & demand-side management & $J$ & maximum number of flames \\
\hline ELF & equivalent loss factor & $T$ & $\begin{array}{l}\text { maximum number of iterations in } \\
\text { the MFOA }\end{array}$ \\
\hline EV & electric vehicle & $b$ & $\begin{array}{l}\text { shape of the logarithmic spiral } \\
\text { constant }\end{array}$ \\
\hline EVSE & $\begin{array}{l}\text { electric vehicle supply } \\
\text { equipment }\end{array}$ & $K$ & single payment present worth factor \\
\hline GA & genetic algorithm & $C R F$ & capital recovery factor \\
\hline GHG & greenhouse gas & $L$ & lifetime of each component [yr] \\
\hline HEM & home energy management & $C C$ & capital cost $[\$]$ \\
\hline IRR & internal rate of return & $S V$ & salvage value $[\$]$ \\
\hline LCOE & levelized cost of energy & $R C$ & replacement cost $[\$]$ \\
\hline MFOA & $\begin{array}{l}\text { moth-flame optimization } \\
\text { algorithm }\end{array}$ & $O \& M$ & operation and maintenance cost $[\$]$ \\
\hline MILP & $\begin{array}{l}\text { mixed-integer linear } \\
\text { programming }\end{array}$ & $R$ & project lifetime $[\mathrm{yr}]$ \\
\hline NPC & net present cost & $L_{\text {rep }}$ & replacement cost duration [yr] \\
\hline PI & profitability index & $L_{\text {rem }}$ & $\begin{array}{l}\text { remaining lifetime of each } \\
\text { component at the end of the } \\
\text { investment horizon }[\mathrm{yr}]\end{array}$ \\
\hline PSO & particle swarm optimization & Variables & \\
\hline PV & photovoltaic & $V(t)$ & wind speed at time step $t[\mathrm{~m} / \mathrm{s}]$ \\
\hline RESs & renewable energy sources & $P_{P V}(t)$ & $\begin{array}{l}\text { output power of PV panels at time } \\
\text { step } t[\mathrm{~kW}]\end{array}$ \\
\hline RTP & real-time pricing & $P_{W T}(t)$ & $\begin{array}{l}\text { output power of WTs at time step } t \\
{[\mathrm{~kW}]}\end{array}$ \\
\hline $\mathrm{SOC}$ & state of charge & $N P C_{\text {index }}$ & $\begin{array}{l}\text { net present cost of each component } \\
\text { (the index shows the corresponding } \\
\text { component) [\$] }\end{array}$ \\
\hline TOU & time-of-use & $N_{\text {index }}$ & $\begin{array}{l}\text { optimum number of each } \\
\text { component (the index shows the } \\
\text { corresponding component) }\end{array}$ \\
\hline WT & wind turbine & $E_{b}(t)$ & $\begin{array}{l}\text { state of charge of the battery bank at } \\
\text { time step } t[\mathrm{kWh}]\end{array}$ \\
\hline Sets and indices & & $P_{c h}(t)$ & $\begin{array}{l}\text { transferred power from the } \\
\text { renewable energy sources to the } \\
\text { battery bank at time step } t[\mathrm{~kW}]\end{array}$ \\
\hline$M, O M$ & $\begin{array}{l}\text { set of moths and their fitness } \\
\text { values }\end{array}$ & $P_{d c h}(t)$ & $\begin{array}{l}\text { transferred power from the battery } \\
\text { bank to the single-phase inverter at } \\
\text { time step } t[\mathrm{~kW}]\end{array}$ \\
\hline
\end{tabular}




\begin{tabular}{|c|c|c|c|}
\hline$F, O F$ & $\begin{array}{l}\text { set of flames and their fitness } \\
\text { values }\end{array}$ & $P_{d u m p}(t)$ & $\begin{array}{l}\text { dissipated power by the dump load } \\
\text { at time step } t[\mathrm{~kW}]\end{array}$ \\
\hline$i$ & index for moths & $P_{\text {load }}(t), P_{\text {lot }}(t)$ & $\begin{array}{l}\text { residential/EV charging loads at } \\
\text { time step } t[\mathrm{~kW}]\end{array}$ \\
\hline$j$ & index for flames & $P_{l o t, d e l}(t)$ & $\begin{array}{l}\text { delivered power to the EV parking } \\
\text { lot at time step } t[\mathrm{~kW}]\end{array}$ \\
\hline Parameters & & $G_{t}(t)$ & $\begin{array}{l}\text { aggregate solar irradiance incident } \\
\text { on the tilted PV panel at time step } t \\
{\left[\mathrm{~W} / \mathrm{m}^{2}\right]}\end{array}$ \\
\hline$A_{m}$ & area of each PV panel $\left[\mathrm{m}^{2}\right]$ & $Q_{\text {load }}(t), Q_{\text {lot }}(t)$ & $\begin{array}{l}\text { loss of residential/EV charging } \\
\text { loads at time step } \mathrm{t}[\mathrm{kWh}]\end{array}$ \\
\hline$V_{r}$ & nominal wind speed $[\mathrm{m} / \mathrm{s}]$ & $r$ & random number in the range $[-1,1]$ \\
\hline$V_{\text {cin }}, V_{\text {cout }}$ & $\begin{array}{l}\text { cut-in and cut-out wind speeds } \\
{[\mathrm{m} / \mathrm{s}]}\end{array}$ & $l$ & number of iteration in the MFOA \\
\hline$P_{r}$ & rated power of WTs $[\mathrm{kW}]$ & $D_{i}$ & $\begin{array}{l}\text { distance from the } i^{\text {th }} \text { moth to the } j^{\text {th }} \\
\text { flame }\end{array}$ \\
\hline$\eta_{c h}$ & $\begin{array}{l}\text { charging efficiency of the } \\
\text { battery bank [\%] }\end{array}$ & $S O D(t)$ & $\begin{array}{l}\text { share of deferred loads in the total } \\
\text { load demand at time step } t\end{array}$ \\
\hline$\eta_{d c h}$ & $\begin{array}{l}\text { discharging efficiency of the } \\
\text { battery bank [\%] }\end{array}$ & Functions & \\
\hline$\eta_{g}, \eta_{l o t}, \eta_{i n v}$ & $\begin{array}{l}\text { PV generation system, EV } \\
\text { parking lot, and single-phase } \\
\text { inverter efficiencies [\%] }\end{array}$ & $I$ & $\begin{array}{l}\text { moths' random population creator } \\
\text { function in the MFOA }\end{array}$ \\
\hline$E_{b, \min }, E_{b, \max }$ & $\begin{array}{l}\text { minimum and maximum } \\
\text { permissible storage potentials of } \\
\text { the battery bank [kWh] }\end{array}$ & $P$ & main function of the MFOA \\
\hline$x$ & $\begin{array}{l}\text { percentage of the total load that } \\
\text { is deferrable }[\%]\end{array}$ & $T$ & $\begin{array}{l}\text { stopping criterion controller } \\
\text { function in the MFOA }\end{array}$ \\
\hline$y$ & $\begin{array}{l}\text { time window of the DR program } \\
{[\mathrm{h}]}\end{array}$ & $S$ & spiral function \\
\hline$D O D$ & $\begin{array}{l}\text { depth of discharge of the battery } \\
\text { packs }[\%]\end{array}$ & rand & random number generator function \\
\hline$\Delta t$ & time step increment $[\mathrm{h}]$ & $N P C_{\text {total }}$ & $\begin{array}{l}\text { total NPC of the micro-grid, i.e. the } \\
\text { objective function }\end{array}$ \\
\hline
\end{tabular}

\section{Introduction}

\subsection{Motivation}

The necessity for reducing greenhouse gas (GHG) emissions, increasing the quality of life, as well as the need for energy diversification, are the driving forces behind the development of clean energy systems for remote communities [1]-[3]. Stand-alone renewable and sustainable energy systems that are situated in proximity of the end-users have been suggested as a substantial solution to resolve many of the issues involved with providing electricity access to remote communities (e.g. high transmission costs due to the long distance and difficult terrain, high GHG emissions, high power losses, etc.) [4], [5].

The introduction of distributed energy resources (DERs) and the advent of green-fuel powered vehicles (e.g. electric and fuel cell vehicles) are two state-of-the-art trends, opening promising prospects for GHG emissions reduction [6], [7]. Nevertheless, the intermittent nature of renewable energy sources (RESs), particularly solar and wind energy, and the expensive capital costs associated with clean technologies, are the two main obstacles that hinder the development of sustainable energy systems in remote areas [8], [9]. In addition, green vehicles can have a significant impact on the total electrical loads on such systems. Therefore, it is necessary to fully integrate the RESs and eco-friendly vehicles into the isolated sustainable 
energy systems to avoid imposing unnecessary costs on the system. As a special form of renewable and sustainable energy systems, the micro-grid concept, by utilizing the smart grid technologies, provides a solution for the cost-effective deployment of RESs and electric vehicles (EVs). The US Department of Energy defines the micro-grid as "a group of interconnected loads and distributed energy resources within clearly defined electrical boundaries that acts as a single controllable entity with respect to the grid" [10].

Moreover, electrical load curves are desired to be as smooth as possible for several reasons, such as mitigating the stress on the electricity generation components, as well as the whole micro-grid, lowering the electricity prices, and deterring or delaying future investments [11]. In this regard, demand-side management (DSM) mechanisms have been used in the power system industry through various approaches (e.g. peak clipping, valley filling, load shifting, flexible load shaping, load conservation, etc.) for many years [12]. These DSM strategies have had very limited scope due to the lack of an efficient integrated infrastructure for the automation of transmission and distribution systems in the power system. However, the advent of smart grid technologies has propelled the integration of DSM strategies, in the form of demand response (DR) programs, into the renewable and sustainable energy systems by providing the required information and communication technology infrastructures. The introduction of EVs has also had an important impact to pave the way for the realization of implementing the large-scale DR programs.

Direct load control (DLC) is one of the most effective and favoured DR programs that is defined as an activity through which the electricity provider can directly control the pre-agreed appliances on the enduser side, which is suitable for every customer that has installed smart meters and appliances. The participation of consumers in DLC programs will be compensated through discounts in their electricity bills, recurring annual payment, one-off signup payment, or free hardware installation [13] [15].

The optimal sizing problem of the components of stand-alone renewable and sustainable energy systems is a non-deterministic polynomial-time hard (NP-hard) combinational optimization problem, whilst also being highly nonlinear and non-convex. This has precluded the use of exact mathematical (analytical) optimization algorithms to solve it [16]. It is firmly believed that such problems cannot be solved to global optimality in polynomial computational time, and solving them requires high computational time. The reason is that as the problem size increases (which is the case in the optimal sizing problem of isolated sustainable energy systems), the time complexity increases exponentially. Hence, finding a feasible technique based on the meta-heuristic optimization approaches, to select the optimal size of the equipment quickly and accurately, has been the focus of the interest of sustainable energy system designers in recent years. In this regard, various meta-heuristic approaches have been employed to solve this problem and have made considerable advances over the last decade [17]. The importance of finding better meta-heuristics for the considered problem lies in that, according to the expensive nature of stand-alone micro-grids, minor enhancements in meta-heuristics utilized in optimal sizing of renewable and sustainable energy systems could have significant positive impacts on the calculated optimal sizes for the components and system's life-cycle cost estimation.

Generally, when an energy system is connected to the upstream energy networks (e.g. electrical grid, natural gas network, hydrogen network, etc.), optimal sizing of its components is slightly less convoluted as it is assumed that it is connected to an infinite energy source, which increases the system's reliability. However, optimal sizing of the stand-alone energy systems is subjected to much more constraints, as they need to meet the demand requirements within their own boundaries, which makes it challenging to solve this problem due to the added nonlinearities and non-convexities. This issue is aggravated in the $100 \%$ renewable energy systems owing to the highly intermittent nature of nearly all of their resources.

\subsection{Objective of the paper}

Based on the above discussion, calculating the optimal size of the equipment of off-grid micro-grids is vital as this promises the cost-efficient supply of electricity, while ensuring the reliability of power supply for 
remote communities. Hence, this paper focuses on developing a method for optimal sizing of the standalone micro-grids by making a maiden attempt to highlight the significance of a new meta-heuristic optimization, whilst employing a DLC-DR program as a DSM strategy. The proposed method has been applied to optimally size the components of an isolated micro-grid that includes photovoltaic (PV) panels, wind turbines (WTs), an EV parking lot, a battery bank, and various power converters.

The specific novelties within the developed method include:

- Modelling a DSM strategy that shifts the deferrable loads on the micro-grid (e.g. a percentage of residential and EV charging loads) from peak to off-peak consumption hours based on the DLCDR scheme.

- Applying a state-of-the-art meta-heuristic optimization algorithm to the considered optimal sizing problem to minimize the whole-life cost of the micro-grid model and proving its superiority over the most favoured and up-to-date meta-heuristics used in the research topic in terms of nearing the optimal solutions.

- Integration of an annual input data compression-based model reduction technique into the proposed optimal sizing method, which enables us to alleviate the computational burden. Accordingly, by comparing the numerical simulation results for a test system in the two cases of with and without data compression using the proposed model reduction technique, the paper aims to validate the findings of Mavrotas et al. [18] on the benefits of model reduction techniques in the planning phase of the energy systems from a broader and more accurate perspective.

Furthermore, comprehensive results and analyses in applying the proposed method to a case study are provided, while an inverse sensitivity analysis of system cost uncovers further effects of the DSM strategy with different outcomes observed due to changes in DR time frame and participated load; i.e. identifies the best values for the input parameters of the DR program.

\subsection{Outline of paper}

The rest of this paper is organized as follows. Section 2 reviews the related literature. Section 3 describes the problem by presenting the architecture and power flow of a conceptual micro-grid test-case system, whereby provides insights on the structure used for evaluating the proposed optimal sizing method. Section 4 presents the mathematical description of the components of the micro-grid test-case system as well as the energy management strategy used for operating the system, while Section 5 introduces the proposed optimal sizing method that integrates the DR programs. Section 6 examines a case study via numerical simulations conducted to demonstrate the effectiveness of applying the developed optimal sizing method on the proposed micro-grid. Finally, the conclusion of this study and future research challenges are presented in Section 7.

\section{Literature review}

There is a considerable amount of literature on different optimal sizing methods for renewable and sustainable energy systems, most of which have used the meta-heuristic optimization algorithms due to the reasons mentioned in the introduction. Several researchers have conducted studies on the application of meta-heuristics for optimal sizing of on-grid renewable energy systems. Maleki et al. [19] have compared the performance of the particle swarm optimization (PSO) and the genetic algorithm (GA) for optimizing a domestic grid-connected hybrid renewable energy system in the planning phase. Moghaddas-Tafreshi et al. [20] have used the breeding PSO for optimal sizing of an on-grid micro-grid subject to satisfying a predetermined loss of power supply probability reliability index. Kefayat et al. [21] have proposed a hybrid ant colony optimization (ACO)-artificial bee colony ( $\mathrm{ABC}$ ) algorithm for probabilistic optimal sizing of DERs within distribution systems. Aman et al. [22] have presented a new approach for the optimal sizing of multi-distributed generation based on the maximization of the system's loadability utilizing a hybrid PSO-ABC technique. Ali et al. [23] have reported on the suitability of the ant lion optimization algorithm 
for optimal sizing of renewable distributed generators for various distribution systems. Furthermore, Mozafar et al. [24] and Ghorbani et al. [25] have highlighted the suitability of the hybrid GA-PSO technique for solving the optimal sizing problem of grid-connected renewable energy systems, which is the most recent meta-heuristic approach proposed in the research area as far as can be ascertained.

In the literature, there are also many examples of applying the meta-heuristics to the optimal sizing problem of islanded renewable energy systems. As an example, Maleki and Pourfayaz [26] have applied the harmony search optimization algorithm to the optimal sizing problem of an autonomous hybrid PV/wind/system power system with battery and fuel cell storage and used the simulated annealing optimization algorithm and HOMER software to validate their results. The authors go further and show that the artificial bee swarm optimization yields the most promising results in terms of accuracy for optimal sizing of isolated renewable energy systems compared with seven other meta-heuristic optimization techniques including the harmony search in [16]. Dong et al. [27] have employed an improved ACO algorithm for optimal sizing of an isolated renewable energy system incorporating WTs, PV panels, a battery bank, an electrolyser, a fuel cell, a hydrogen tank, and an inverter. Similarly, Kaabeche et al. [28] have highlighted the advantages of using the firefly algorithm for optimal sizing of a grid-independent hybrid renewable energy system considering the load dissatisfaction rate and an electricity cost indicator for estimating the power supply reliability and system costs, respectively. Shang et al. [29] have used an improved PSO algorithm for optimal sizing of the battery banks in stand-alone hybrid renewable energy systems. Nagapurkar and Smith [30] have used the GA for the optimal sizing and siting of a small-scale micro-grid system comprised of PV panels, WTs, lead-acid battery modules, a biodiesel generator, a fuel cell, an electrolyser, and a hydrogen reservoir. Sawle et al. [31] have calculated the optimal configuration of a stand-alone PV/wind/biomass hybrid energy system using both the GA and PSO techniques, which are the two most well-known algorithms for optimal sizing of renewable and sustainable energy systems in the literature. It is worthwhile noting that according to the no free lunch theorem [32] (which demonstrates that there exists no meta-heuristic optimizer properly suitable for solving various types of optimization problems), finding a more efficient meta-heuristic optimization algorithm for solving the considered problem compared with the status quo remains an ongoing process. Detailed literature reviews on different size optimization methodologies applied to various configurations of stand-alone renewable and sustainable energy systems are given in [33]-[37].

An increasing number of studies have focused on the impact of DR programs in the planning phase of gridconnected renewable and sustainable energy systems, most of which are involved with shifting some of the loads from peak to off-peak consumption hours in response to the electricity prices. As an example, Erdinc et al. [38] have developed a mixed-integer linear programming (MILP) model for optimal sizing of additional PV and battery packs for smart households that incorporates a home energy management (HEM) system, which operates based on the dynamic pricing DR programs. Nojavan et al. [39] have reported on a new method for optimal sizing of the energy storage system in an on-grid micro-grid and considered a timeof-use (TOU) rate as a DSM strategy. Zheng et al. [40] have proposed a sliding time window optimization modelling technique to optimally design a combined heat and power micro-grid system under the TOU tariff. Zheng et al. [41] go further and develop a load shifting algorithm based on the state of renewable energy generation and TOU tariff using linear programming, while optimally designing a biomassintegrated micro-grid. Similarly, Amir et al. [42] have reported on a two-stage method for optimal planning and scheduling of a multi-carrier micro-grid under the TOU pricing scheme. Hakimi and MoghaddasTafreshi have optimally sized a smart micro-grid that incorporates domestic flexible loads. They have considered the washing machine as a flexible load and proved that DSM contributes to reducing the lifecycle costs of on-grid micro-grids by decreasing the sizes of their components and reducing their dependence on the up-stream distribution systems. Hakimi and Moghaddas-Tafreshi [43] go further and investigate the potential benefits of using an active controller applied to heating/cooling systems in the context of DR, while optimally planning a smart micro-grid. Pazouki and Haghifam [44] have presented a new method for optimal planning and operation of an energy hub considering DR programs as the renewable energy resources' complements. They have formulated the DR programs such that they respond to fluctuations in the electricity price, electricity demand, and wind power. Kahrobaee et al. [45] have 
considered the real-time pricing (RTP) demand response programs, while optimally sizing the distributed generation and electricity storage system in smart households. Liu et al. [46] have highlighted the potential value of integrating DR schemes into the long-run investment planning studies of smart energy hubs, where the DR concept could be delivered within two forms: (1) the classic flexibilization of the demand for electricity, and (2) inter-conversion of different energy forms.

Unlike grid-connected renewable energy systems, few researchers have highlighted the effectiveness of DR programs in optimal planning studies of isolated renewable energy systems. Chauhan and Saini [47] have implemented a DR strategy based on the energy consumption scheduling of appliances, while optimally sizing a stand-alone renewable energy system incorporating the micro-hydro power, biogas, solar, and wind energy sources using the discrete harmony search algorithm. By optimizing the system with and without considering the proposed DR strategy, they have demonstrated that the DR strategy contributes to significant amounts of savings in sizes of the components of the system as well as its whole-life cost. Similarly, Amrollahi and Bathaee [48] have calculated the optimal size of the equipment of a stand-alone micro-grid, that consists of PV arrays, WTs, battery packs, and an inverter, which is subjected to a DR program. They have classified the electrical loads into the dispatchable and non-dispatchable loads and implemented the DR program using the dispatchable loads. Based on the numeric simulation results and scenario comparisons conducted for a test-case system, they have affirmed that their proposed DR strategy, by reducing the imbalance between the power generation and consumption profiles, contributes to reducing the number of batteries, inverters, and PV arrays and, consequently, reduces the total net present cost (NPC) of the micro-grid. Zhu et al. [49] have evaluated the impacts of integrating the DLC scheme, as a DR program, into the integrated resources planning phase of an isolated micro-grid. On the basis of the obtained numeric simulation results, they have deduced that their developed method, which utilizes the load shifting capability of controllable loads, provides an effective technique to achieve the minimum planning costs for isolated micro-grids. They have also proved that as the proportion of controllable loads in the system increases, the profitability of implementing the load shifting DR programs in the planning phase of microgrids does so as well.

The optimal planning problem of the renewable and sustainable energy systems using the meta-heuristic optimization algorithms is intrinsically computationally demanding. Therefore, developing a technique that ensures the computational tractability, while solving such problems, is vital. In this regard, Mavrotas et al. [18] have proposed a model reduction technique, whereby the load demand data of the model are compressed. By comparing different models for grouping load demand data, they have concluded that the data compression-directed model reduction up to the $3 \times 6$ representative model (i.e. 3 representative times of year with 6 time-windows throughout the day) is useful in optimal planning studies of energy systems as it drives in much faster convergence times without having a significant negative impact on the accuracy of the solutions obtained. Their approach is not well suited to the optimal sizing problems of renewable and sustainable energy systems as they consider the monthly averaged daily profiles for the load demand as the full model and further reduce it through a model reduction technique, whereas the full model for the meteorological and load demand input data of the aforementioned sizing problems should at least be one year to consider the seasonal and weekday-weekend impacts on load demand as well as the variability of the weather-driven sources [38]. Similarly, Liu et al. [50] have used the monthly averaged wind speed, solar irradiance, temperature, and load power consumption data, while optimally sizing the components of a wind/PV/battery system. Furthermore, HassanzadehFard et al. [51] and Hakimi et al. [52] have considered the weekly means of the annual input data, while assessing the effect of energy storage systems on the optimal sizing of an islanded PV/wind/fuel cell/battery micro-grid and calculating the optimal sizes of a stand-alone wind/fuel cell hybrid power system, respectively. Although the approaches used by Liu et al. [50], HassanzadehFard et al. [51], and Hakimi et al. [52] are in line with the goals of computational complexity reduction, they have failed to demonstrate that their results are comparable with an unreduced model. 
The above-discussed studies, along with many other research efforts not referred to here, have offered useful contributions to the optimal equipment capacity planning of the renewable and sustainable energy systems in terms of either the improving the optimization protocol or deploying a DR program. However, no one, as far as can be ascertained, has studied the potential advantages of applying the moth-flame optimization algorithm (MFOA), as well as implementing a DLC-DR program using deferrable loads, while optimally sizing the components of the grid-independent micro-grids equipped with an EV parking lot for remote communities. The aim of our work is to expand the current knowledge of applying meta-heuristics for optimal sizing of the sustainable energy systems as well as implementing appropriate DSM strategies in their planning phase, with an eye towards computational cost reduction through the use of a data compression-based modelling framework.

\section{Micro-grid test-case system modelling}

This section briefly describes the problem by introducing the components, configuration, and power flow of the proposed off-grid micro-grid for rural areas, which is used as the test-case system to verify the effectiveness of the proposed optimal sizing method. It also includes a brief overview of the micro-grid's operational strategy, which is used in the procedure of calculating the optimal sizes of the micro-grid components.

The proposed stand-alone micro-grid for remote areas incorporates PV panels, WTs, a battery bank, an EV parking lot, as well as various power converters (a single-phase DC/AC inverter, a three-phase DC/AC inverter, a three-phase AC/DC converter, and a single-phase DC/DC converter). The proposed micro-grid is a $100 \%$ renewable energy system, which is most beneficial for locations where the wind and solar resources complement each other on a day-to-day basis over the year - making the wind and solar resources great options for electricity generation and reducing the size of the required energy storage system (i.e. the battery bank in the proposed micro-grid). Furthermore, the AC/DC and DC/DC converters are considered in the micro-grid structure so that the WTs and PV panels can be respectively tied to a common DC bus. Moreover, the EV chargers used in the parking lot are coupled to the micro-grid network through a threephase $\mathrm{DC} / \mathrm{AC}$ inverter. It is to be noted that the costs and efficiencies associated with the aforementioned $\mathrm{AC} / \mathrm{DC}, \mathrm{DC} / \mathrm{DC}$, and three-phase DC/AC converters are included in the costs and efficiencies associated with the WTs, PV panels, and electric vehicle supply equipment (EVSE), respectively; therefore, their sizes are dependent on the sizes of their respective components as well, and are not calculated separately in this study. But, the size of the single-phase DC/AC inverter used to serve the AC residential loads on the microgrid participates in the optimal sizing procedure.

The structure of the proposed micro-grid is depicted in Fig. 1. As can be seen in the figure, the output power from the PV and wind generation systems are denoted by $P_{P V}[\mathrm{~kW}]$ and $P_{W T}[\mathrm{~kW}]$, respectively. As stated previously, calculating the optimal sizes of the AC/DC, DC/DC, and three-phase DC/AC converters has not been considered in this study due to the dependence of their sizes to their respective component; therefore, they are shown inside the dashed lines in Fig. 1. Furthermore, as the EVs are not charged using the energy stored in the battery bank due to the energy efficiency considerations, the DC input of the threephase inverter can only source from the PV panels and WTs. The electrical loads on the micro-grid are consisted of: (i) residential loads $\left(P_{\text {load }}\right)$, (ii) EV charging loads $\left(P_{\text {lot }}\right)$, and (iii) a DC dump load $\left(P_{\text {dump }}\right)$ that dissipates the excess power generated by renewable sources. Furthermore, it is assumed that the hourly load profiles for the residential loads and parking lot for a typical year are available and forecasting these load profiles based on the historical data or by using a synthetically generated historical data (based on whether the historical data regarding the residential loads and charging demand of the EV parking lot for the considered case study site are available or not) falls outside the scope of this paper.

Moreover, as there are some time steps at which the required charging demand of the EVs is not provided, the delivered power to the EV parking lot is different from the requested demand of the lot, which is denoted by $P_{l o t, d e l}$ in this project. Note that unlike the year-round profile for $P_{l o t}$, which is known in advance, the 
profile for $P_{l o t, d e l}$ is determined by operating the system using the calculated optimal combination of the size of the micro-grid's equipment.

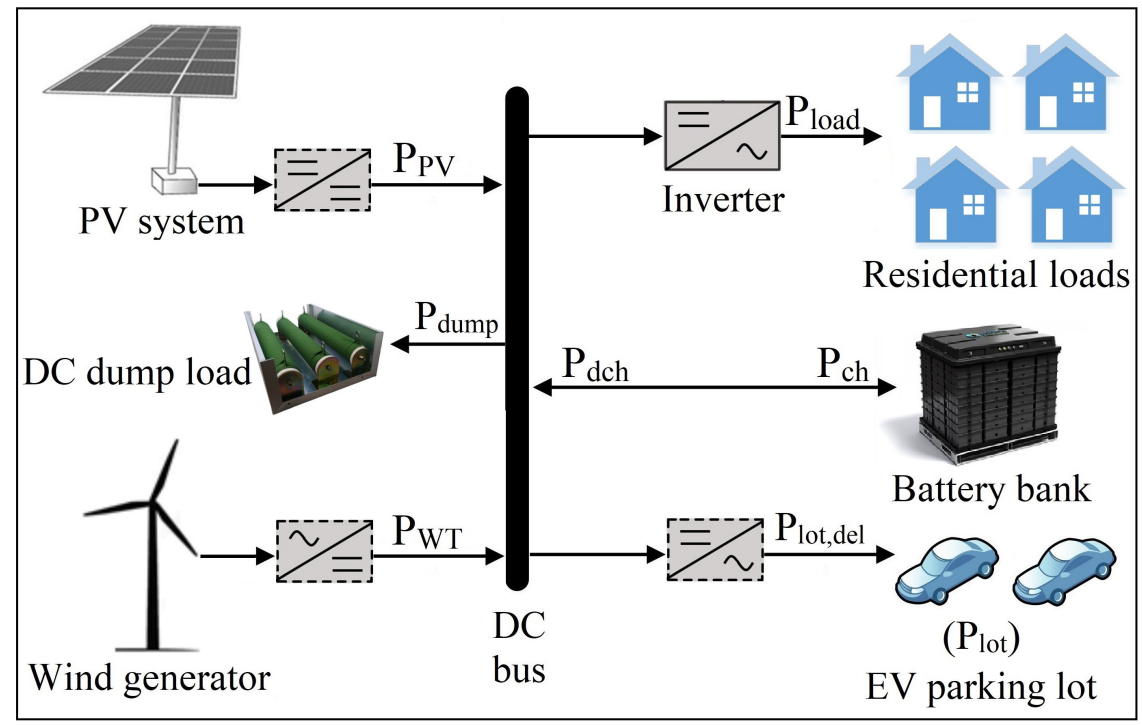

Fig. 1. Schematic diagram of the conceptualized off-grid micro-grid.

\section{Micro-grid components and operational strategy}

In this section, the components of the proposed micro-grid that are considered in the optimal sizing procedure (i.e. their optimal sizes are under investigation) are described mathematically and their product models, specifications and economic parameters are also presented before describing the operational strategy of the micro-grid.

\subsection{Mathematical modelling and specifications of the micro-grid units}

\subsubsection{PV panel}

The output power of the PV generator at time step $t$ can be calculated by the following equation [53]:

$$
P_{P V}(t)=N_{P V} \times \eta_{g} \times A_{m} \times \frac{G_{t}(t)}{1000},
$$

where $\eta_{g}$ is the efficiency of the PV panels, $A_{m}$ is the area of each PV panel $\left[\mathrm{m}^{2}\right], G_{t}(t)$ is the aggregate solar irradiation incident on the tilted PV panels $\left[\mathrm{W} / \mathrm{m}^{2}\right]$ at time step $t$, and $N_{P V}$ is the optimum number of panels that is determined at each iteration of the optimal sizing procedure. In this project, Canadian Solar CS6U-325P, which is a polycrystalline PV panel is considered. It has a rated capacity of $325 \mathrm{~W}$ and its lifetime is equal to 25 years. The efficiency and area of each panel is $16.94 \%$ and $1.92 \mathrm{~m}^{2}$, respectively. Furthermore, the capital, replacement, and operation and maintenance (O\&M) costs of each panel are equal to $\$ 700, \$ 500$, and $\$ 14 /$ year, respectively. Moreover, a derating factor of $85 \%$ is also considered to take account the reduced output power from the PV generation system due to real-world conditions such as shading, wiring losses as well as dust and snow cover [54].

\subsubsection{Wind turbine}

The output power of the WT generation system at time step $t$ can be determined as follows [55]:

$$
P_{W T}(t)=N_{W T} \times \begin{cases}0 & ; V<V_{\text {cin }}, V>V_{\text {cout }} \\ P_{r} \times\left(\frac{V(t)-V_{\text {cin }}}{V_{r}-V_{\text {cin }}}\right)^{3} & ; V_{\text {cin }} \leq V<V_{r} \\ P_{r} & ; V_{r} \leq V \leq V_{\text {cout }}\end{cases}
$$


where $V_{\text {cin }}, V_{\text {cout }}$, and $V_{r}$ represent the cut-in, cut-out, and rated wind speeds, respectively. Also, $V(t)$ and $N_{W T}$ are the wind speed at time step $t$ and the optimal number of WTs, respectively. In this analysis, Eocycle EO10 WT, which is a 3 Blade Upwind WT, is considered. It has a rated capacity of $10 \mathrm{~kW}$, a lifetime of 20 years, and its cut-in, cut-out, and rated wind speeds are equal to $2.75,20$, and $7.5 \mathrm{~m} / \mathrm{s}$, respectively. Furthermore, both the capital and replacement costs of the WT are considered as $\$ 30,000$, which includes the costs associated with the controller and tower as well as installation costs, while its O\&M cost is considered as $\$ 600 /$ year [54].

\subsubsection{Battery bank}

The following equation can be used to model the state-of-charge (SOC) of the battery bank at each time step $t[56]$ :

$$
E_{b}(t)=E_{b}(t-1)+P_{c h}(t) \times \eta_{c h} \times \Delta t-\left(\frac{P_{d c h}(t)}{\eta_{d c h}}\right) \times \Delta t,
$$

where $P_{c h}$ is the delivered electricity from the renewable energy sources to the battery packs, $P_{d c h}$ is the delivered electricity from the battery modules to the single-phase inverter, and $\eta_{c h}$ and $\eta_{d c h}$ are the charging and discharging efficiencies of the battery bank, respectively that both of them are considered as $85 \%$ in this study [57].

At each time step $t$, the storage capacity of the battery bank is subject to the following constraints [58]:

$$
E_{b, \min } \leq E_{b}(t) \leq E_{b, \max },
$$

where $E_{b, \min }$ and $E_{b, \max }$ represent the minimum and maximum permissible storage potentials of the battery bank.

In this study, $E_{b, \max }$ denotes the nominal capacity of the battery bank, which is controlled by the optimal capacity of the battery bank (that is calculated at each iteration of the optimal sizing procedure). Furthermore, $E_{b, \min }$ is controlled by the battery bank's maximum permissible depth of discharge (DOD), which can be described by Eq. (5) [58].

$$
E_{b, \min }=\frac{(100-D O D)}{100} \times E_{b, \max } .
$$

The maximum allowable DOD of the battery bank is considered as $85 \%$ in this analysis [59]. Furthermore, it is assumed that the battery packs are half full charged initially and in order to avoid undersizing of the battery bank, due to this assumption, a constraint is incorporated in the proposed optimal sizing method. This ensures that the amount of energy stored in the battery bank at the end of the optimization process is not less than its amount at the beginning.

The Rolls Surrette 6CS25P (6-CS-25P) battery pack, which is a $6 \mathrm{~V}$ battery rated at 1,156 Ah (i.e. 6.936 $\mathrm{kWh}$ ), is considered in this project. It has a lifetime of 10 years and its charge and discharge efficiencies are equal to $95 \%$. Also, the capital and replacement costs are assumed as $\$ 1229$, and the O\&M cost $\$ 25 /$ year [60].

\subsubsection{EV parking lot}

The EVSE is considered in this analysis to charge the batteries of the EVs that utilize the parking lot's infrastructure. The EVSE is also able to communicate with the EVs with the objective that the charging mechanism happens in a protected way. In this analysis, Keba B-series EVSE, which is a $22 \mathrm{~kW}$ type $2 \mathrm{EV}$ charger, is used. The efficiency of the considered EV chargers are denoted by $\eta_{l o t}$, which is considered to be $90 \%$ in this study and their lifetime is 20 years. The considered EVSE is operated with a three-phase 
supply voltage of $415 \mathrm{VAC}$ and accepts a maximum current of $32 \mathrm{~A}$. Both the capital and replacement costs of each EVSE are considered as $\$ 4000$, which includes the costs associated with the three-phase inverter, and the O\&M cost is considered as $2 \%$ of the capital cost (i.e. $\$ 70 /$ year).

\subsubsection{DC/AC converter}

A single-phase inverter is included in the system, by which the residential loads are coupled to the microgrid network. The DC input of the inverter can source from the DC output of the WTs, PV generator, and the battery bank.

In this study, a generic single-phase inverter is considered. The efficiency $\left(\eta_{i n v}\right)$ and lifetime of the inverter are equal to $90 \%$ and 15 years, respectively. The capital, replacement, and O\&M costs of the inverter are considered as $\$ 750 / \mathrm{kW}, \$ 750 / \mathrm{kW}$, and $\$ 15 / \mathrm{kW} /$ year, respectively [54].

\subsection{Operational strategy}

Three main situations are considered for the operation of the micro-grid that model the power flow of the micro-grid based on different levels of electricity generation and demand, which are described in the following.

\subsubsection{Generation meets demand}

In such a situation, the power generated by PV panels and WTs equals to the sum of residential loads and charging demand of the parking lot; hence,

$$
\begin{aligned}
P_{P V}(t)+P_{W T}(t) & =\left(P_{l o a d}(t) / \eta_{\text {inv }}\right)+\left(P_{l o t}(t) / \eta_{l o t}\right), \\
& E_{b}(t+\Delta t)=E_{b}(t), \\
& P_{l o t, d e l}(t)=P_{l o t}(t) .
\end{aligned}
$$

\subsubsection{Over-generation}

In such circumstances, where the power generated from renewable sources is more than the aggregate power requirements of the residential loads and parking lot, the surplus power $\left(P_{c h}[\mathrm{~kW}]\right)$ will be utilized for charging of the battery modules; hence,

$$
\begin{gathered}
P_{c h}(t)=P_{P V}(t)+P_{W T}(t)-\left(P_{\text {load }}(t) / \eta_{\text {inv }}\right)-\left(P_{\text {lot }}(t) / \eta_{l o t}\right), \\
E_{b}(t+\Delta t)=E_{b}(t)+P_{c h}(t) \times \eta_{c h} \times \Delta t, \\
P_{\text {lot }, \text { del }}(t)=P_{\text {lot }}(t) .
\end{gathered}
$$

When the delivered power to the battery bank is beyond its nominal power, the surplus energy will circulate in the dump DC load.

\subsubsection{Over demand}

In the time steps that there is a shortage in renewable power generation to satisfy the residential loads, the battery bank will be discharged to the amount of $P_{d c h}[\mathrm{~kW}]$ to compensate for the shortfalls in power generation; hence,

$$
\begin{gathered}
P_{d c h}(t)=\left(P_{\text {load }}(t) / \eta_{\text {inv }}\right)-P_{P V}(t)-P_{W T}(t), \\
E_{b}(t+\Delta t)=E_{b}(t)-\left(P_{d c h}(t) / \eta_{d c h}\right) \times \Delta t, \\
P_{\text {lot,del }}(t)=0 .
\end{gathered}
$$

When the amount of energy stored in the battery bank is not enough for compensating for the power shortfalls, a residential load-shedding scheme ensures the balance of power between the generation and consumption in the conceptualized MG system. 
In this situation, the loss of residential and EV charging loads at time step $t[\mathrm{kWh}]$ can be calculated by Eqs. (9) and (10), respectively.

$$
\begin{gathered}
Q_{\text {load }}(t)=P_{\text {load }}(t)-\left(P_{P V}(t)+P_{W T}(t)+\left(\frac{E_{b}(t)-E_{b, \text { min }}}{\Delta t}\right) \times \eta_{d c h}\right) \times \eta_{\text {inv }}, \\
Q_{\text {lot }}(t)=P_{\text {lot }}(t) .
\end{gathered}
$$

\section{Proposed micro-grid equipment capacity planning method}

The proposed optimal sizing method for stand-alone micro-grids consists mainly of five parts: (1) a model reduction technique, (2) a DLC-DR program, (3) a reliability assessment plan, (4) an objective function, and (5) a state-of-the-art meta-heuristic optimization algorithm, i.e. the MFOA, which are described in detail in the following sub-sections.

\subsection{Data compression-based model reduction technique}

As stated previously, optimal sizing of a micro-grid is inherently a computationally expensive problem, which necessitates the simplification of the model as far as possible without having a considerable negative impact on the optimality of the solution. Accordingly, inspired by [18], a model reduction technique is utilized in this study to alleviate the computational cost. In this regard, based on the hourly-basis, yearround profiles for residential loads, EV charging power requirements of the parking lot, solar irradiance, and wind speed ( 8760 data points per data stream), the monthly averaged daily profiles for the abovementioned parameters are derived and a $12 \times 24$ model ( 288 data points per data stream) is developed.

\subsection{Direct load control-demand response program}

Given that the proposed micro-grid in this study is a smart energy system that provides coherent $100 \%$ renewable energy solutions (to satisfy the residential demand for electricity and decarbonize the transport sector), it is associated with low power generation flexibility. This emphasizes the need for adopting an appropriate DR program, whereby the low power generation flexibility of the micro-grid system could be compensated for, remarkably.

Accordingly, among all the DR programs, the DLC, which is an incentive-based DR program, is integrated into the proposed optimal sizing method by deploying smart meters and controllers in the smart grid milieu to remotely control a portion of the end-users' appliances and shift an appropriate percentage of the electrical load on the micro-grid system from peak to off-peak consumption hours. The reason behind selecting the DLC-DR program in this study lies in its simplicity and the fact that it can give more realistic results compared with the adoption of price-based DR programs in the planning phase of stand-alone renewable energy systems. This is because implementing a DR program through directly (supervisedly) controlling the loads is subject to a lower level of uncertainty than the price-based DR programs. The integrated DLC-DR program into the proposed optimal sizing method is explained below.

As mentioned before, two categories of electric load demand should be supplied using the proposed microgrid for remote communities in this study: (1) residential and (2) EV charging loads. The proposed DR scheme in this study starts by segmenting the total load on the micro-grid into the deferrable and nondeferrable loads. In this regard, it is assumed that at each hour, $x$ percent of the total load is deferrable and supplying them can be deferred by up to $y$ hours. These loads are assumed to be uninterruptible, but deferrable, which means that they can be shifted in time, but can no longer be shifted once scheduled. The rest of the loads are considered to be non-deferrable or critical loads. Accordingly, in addition to the EV charging demand of the parking lot, the following domestic loads can be considered as deferrable loads: dish washers, heating, ventilation, and air conditioning, washing machines, clothes dryers, lighting, water pumps, as well as heat-pump water and space heaters loads. The DR strategy then adds the considered value for the deferrable loads to the total load curve of the micro-grid over the next $y$ hour period. By comparing the resulted values with the current value of the load at each time step, $t$, the deferrable loads are then 
shifted to the time step at which the accumulated load is minimum if it is lower than the current value of the total load on the micro-grid. Applying this scheme, the new profile for the total electrical load is calculated and integrated into the proposed optimal sizing method. It is worthwhile noting that the appropriate values for $x$ and $y$ are case-specific and depend on the consumers' behavior at each remote community - so that a predetermined level of consumers' comfort is preserved. In this regard, conducting a survey on the preferences of the end-users for load shifting could be of significant importance towards the success of the considered DSM strategy.

\subsection{Reliability evaluation}

The equivalent loss factor (ELF) is used in this paper as an index to assess the micro-grid's reliability level because it gives details about both the frequency and degree of the outages that happen in the system [61]. The ELF criteria for evaluating the reliability of supplying the residential and EV charging loads can be calculated by Eqs. (11) and (12), respectively [61].

$$
\begin{gathered}
E L F_{\text {load }}=\frac{1}{n} \sum_{t=1}^{n} \frac{Q_{\text {load }}(t)}{P_{\text {load }}(t)}, \\
E L F_{\text {lot }}=\frac{1}{n} \sum_{t=1}^{n} \frac{Q_{\text {lot }}(t)}{P_{\text {lot }}(t)},
\end{gathered}
$$

where $n$ represents the number of time steps in which the reliability of the system is assessed (i.e. the operational time frame), which is considered as 288 in this study as a result of reducing the model. In this study, ELF load is assumed to be lower than 0.01. It should be noted that although the ELF index for supplying the domestic loads is below 0.0001 in developed countries, it is generally accepted that the values of 0.01 or lower are adequate for supplying electricity to remote communities [62]. Furthermore, ELF lot is assumed to be lower than 0.02 in this analysis.

\subsection{Objective function}

The NPC concept is used in this study to compute the whole-life cost of the micro-grid test-case system. The NPC of each MG element is defined as follows [55]:

$$
N P C=N \times\left(C C+R C \times K+O \& M \times \frac{1}{C R F(\text { ir }, R)}\right),
$$

where $C C, R C$, and $O \& M$ represent the capital, replacement, and operation and maintenance costs, respectively; and $C R F$ and $K$ denote the capital recovery and single payment present worth factors, respectively. These variables are described by Eqs. (14)-(16) [55].

$$
\begin{gathered}
C R F(\text { ir }, R)=\frac{i r(1+i r)^{R}}{(1+i r)^{R}-1}, \\
K=\sum_{p=1}^{Y} \frac{1}{(1+i r)^{L \times p}}, \\
Y= \begin{cases}{\left[\frac{R}{L}\right]-1} & \text { if } R \text { is dividable to } L, \\
{\left[\frac{R}{L}\right]} & \text { if } R \text { is not dividable to } L,\end{cases}
\end{gathered}
$$


where $N$ is the optimal size of each component, ir denotes the real interest rate that is assumed as $6 \%, R$ is the project lifetime [yr] that is considered as 25 years (in compliance with the lifetime of the PV panels as the most durable component of the system), and $L$ represents each component's lifetime [yr].

The salvage value for the components having a shorter lifetime than the projected lifetime of the system is calculated according to Eqs. (17)-(19) [63].

$$
S V=R C \times \frac{L_{r e m}}{L},
$$

where $L_{r e m}$ represents the remaining lifetime of each component at the end of the project lifetime, which can be calculated by the following equation:

$$
L_{\text {rem }}=L-\left(R-L_{\text {rep }}\right),
$$

where $L_{r e p}$ denotes the replacement cost duration, which can be calculated according to the following equation:

$$
L_{\text {rep }}=L \times\left[\frac{R}{L}\right] .
$$

The total NPC of the micro-grid is considered as the objective function that can be described by Eq. (20).

$$
N P C_{\text {total }}=N P C_{P V}+N P C_{W T}+N P C_{\text {bat }}+N P C_{\text {inv }}+N P C_{E V S E}+\text { pen }_{\text {load }}+\text { pen } \text { lot }+ \text { pen } n_{\text {bat }} \text {, }
$$

where $N P C_{P V}, N P C_{W T}, N P C_{b a t}, N P C_{i n v}$, and $N P C_{E V S E}$ represent the NPCs of the PV panels, WTs, battery packs, the inverter, and the EVSE, respectively; pen load $_{\text {lond }}$ pen $n_{\text {lot }}$ are two penalty factors that are utilized to convert the aforementioned reliability indices to infinite costs when the considered reliability constraints are not met (note the single-objective formulation of the problem); and $p e n_{b a t}$ is a penalty factor utilized to incorporate the constraint on the SOC of the battery bank at the end of the operational time frame into the optimal sizing method by adding an infinite cost to the total NPC of the micro-grid in the cases that it has not been satisfied.

The objective function is to be minimized using four different meta-heuristic optimization algorithms: the MFOA [64], the GA [65], the PSO [66], and the hybrid GA-PSO [67]. The MFOA is incorporated into the proposed method as the prime optimizer, while the GA, the PSO, and the hybrid GA-PSO are adopted to test and verify the effectiveness of the MFOA. In this sense, a brief introduction to the MFOA is provided as supplementary material accompanying the paper (Additional file 1: The moth-flame optimization algorithm). Moreover, the detailed pseudo-codes of all the four algorithms are given as supplementary material accompanying the paper (Additional file 2: Algorithms S1-S4).

\subsection{An overview of the developed optimization process for the micro-grid sizing}

The flowchart of the proposed optimal sizing method is shown in Fig. 2. The inputs to the model are the hourly climatic data of the considered case study site; hourly load demand data on the proposed micro-grid; product model, specifications, and economic parameters of the micro-grid components; operating characteristics of the DSM strategy including the time window of the DLC-DR program and the proportion of the loads that participate in the DR program; as well as the project lifetime and interest rate. The model is then reduced through implementing the data compression-based model reduction technique to the monthly-averaged daily meteorological and load demand data. This is followed by implementing the DR program that shifts a predetermined percentage of the residential and EV charging loads from peak to offpeak consumption hours. The objective function is then iteratively minimized to calculate the optimal sizes of the micro-grid components, whilst the system is operated using the obtained sizes. At this stage, the 
micro-grid system's operational constraints are checked. In order to ensure that the deferred loads are not shed in the procedure of satisfying the reliability indices (illustrated in sub-section 5.3), the constraint given in Eq. (21) is checked for each time step, $t$, of the operational time frame so that the convenience of the micro-grid customers is guaranteed. Furthermore, according to the constraint in Eq. (4), the energy storage capacity of the battery bank should lie in a certain range at each time step.

$$
Q_{\text {load }}(t)+Q_{\text {lot }}(t) \leq(1-S O D(t)) \times\left(P_{\text {load }}(t)+P_{\text {lot }, \text { del }}(t)\right),
$$

where $\operatorname{SOD}(t)$ is a time-dependent variable, which determines the share of deferred loads in the total load demand at time step $t$ and can take values between zero and one.

When the above-mentioned constraints are satisfied, the system constraints in the planning level are checked. Accordingly, if the $E L F_{\text {load }}$ is less than 0.01, ELF lot is less than 0.02, and the energy content of the battery bank in the last hour of the operational time frame is not lower than its initial energy content, then the calculated sizes of the components will be decided as the optimum sizes.

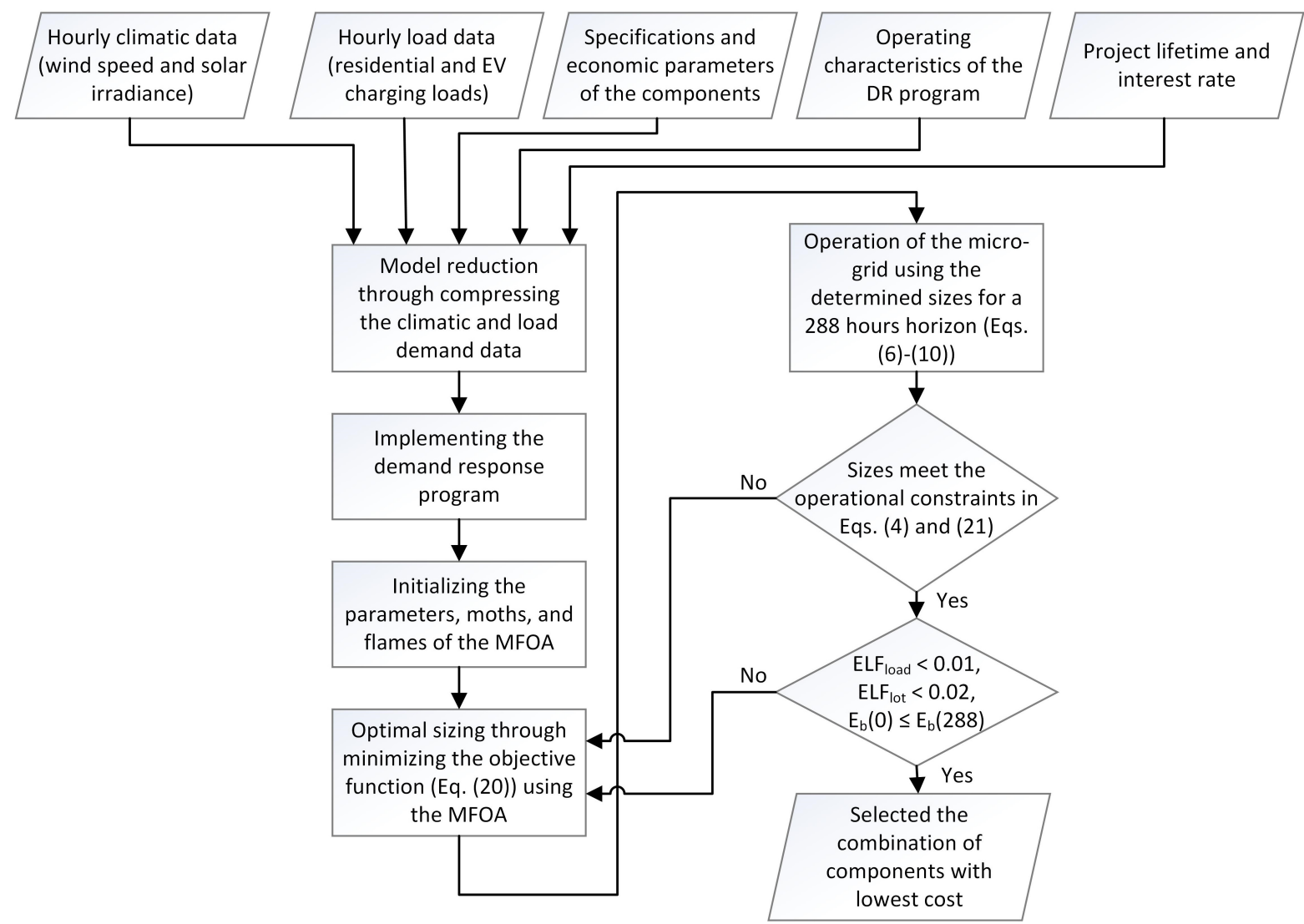

Fig. 2. Flowchart of the proposed optimal sizing method.

\section{Simulation results and discussion}

The proposed micro-grid shown in Fig. 1 (which can be considered as a typical stand-alone micro-grid for providing electricity access to remote areas), is employed to test and verify the efficacy of the devised optimal sizing method. This is conducted by analyzing the impacts of the novel aspects incorporated in the method compared with the most commonly used approaches in the planning studies of micro-grids via numerical simulations. All simulations were conducted on the Intel ${ }^{\circledR}$ Core ${ }^{\mathrm{TM}} \mathrm{i} 7-4770 \mathrm{CPU}, 3.40 \mathrm{GHz}$ using the MATLAB software. 


\subsection{Input data}

A case study was undertaken to calculate the optimal size of the equipment of the conceptualized standalone micro-grid for Hengam Island, Iran (latitude 26.6536-degree north and longitude 55.8802-degree east). Located around 35 kilometres off the southern coast of Iran, the island has a great wind energy potential and a good solar resource with low seasonal variations for electricity generation.

The climatic data for the considered site was obtained from the Iran Meteorological Organization and the one-year, hourly-averaged data on solar irradiance and wind speed is extracted from the climatic data recorded for the period 2006-2018. The monthly averaged daily solar irradiance and the monthly mean wind speed extracted from the aforementioned one-year hourly data are shown in Figs. 3 and 4, respectively. Furthermore, the monthly mean values of the forecasted hourly total electrical load on the proposed microgrid over a year, including the residential and EV charging loads before adopting the considered DLC-DR program is shown in Fig. 5. In fact, the accurate forecasting of the electrical load on the proposed microgrid was beyond the scope of this study and the load demand is simply estimated based on the population of the island (i.e. 615) and the number of EVs integrated into the system (i.e. 60), which is scaled according to the typical domestic daily electrical load curve and daily charging load demand of EVs proposed in [68] and [69], respectively.

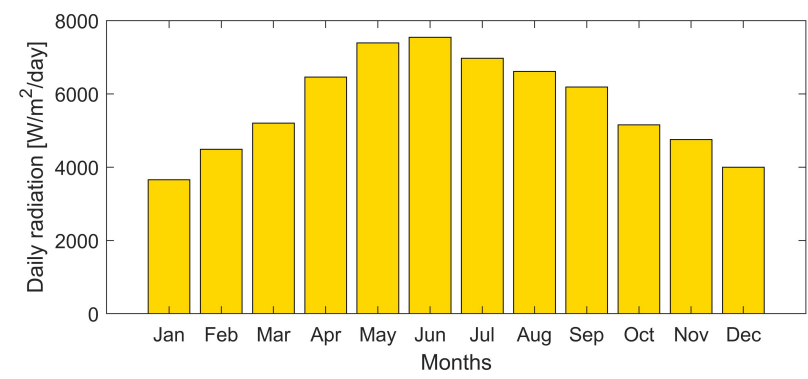

Fig. 3. Monthly averaged daily solar irradiance at the considered site.

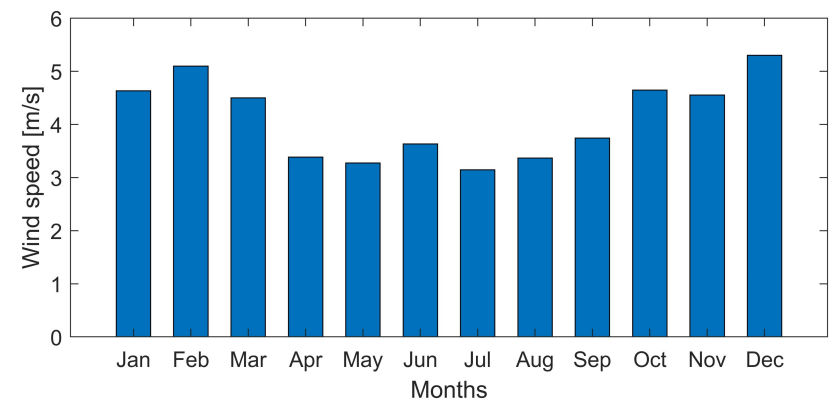

Fig. 4. Monthly mean wind speed at the considered site.

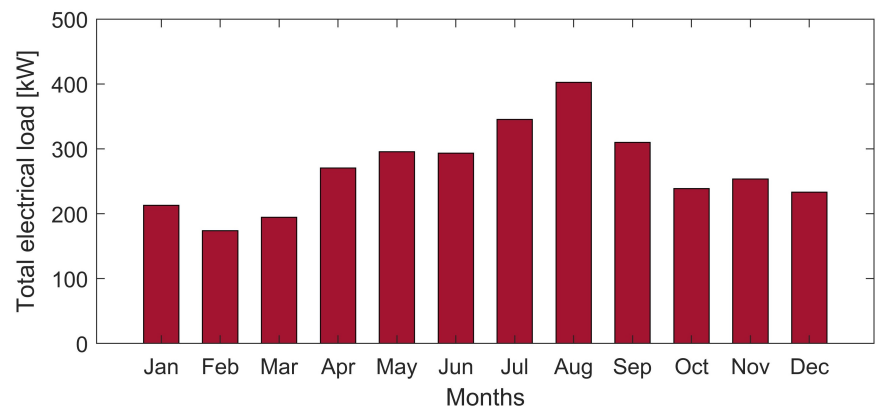

Fig. 5. Monthly mean electrical load on the conceptualized micro-grid. 
Moreover, the monthly averaged 24-h profiles for the solar irradiance and wind speed at the considered site are shown in Fig. 6. As it can be inferred from Fig. 6, wind and solar resources have strong complementary characteristics both over the day and year, favourably supporting their integration into the proposed microgrid, whilst ensuring consistent and efficient power generation.

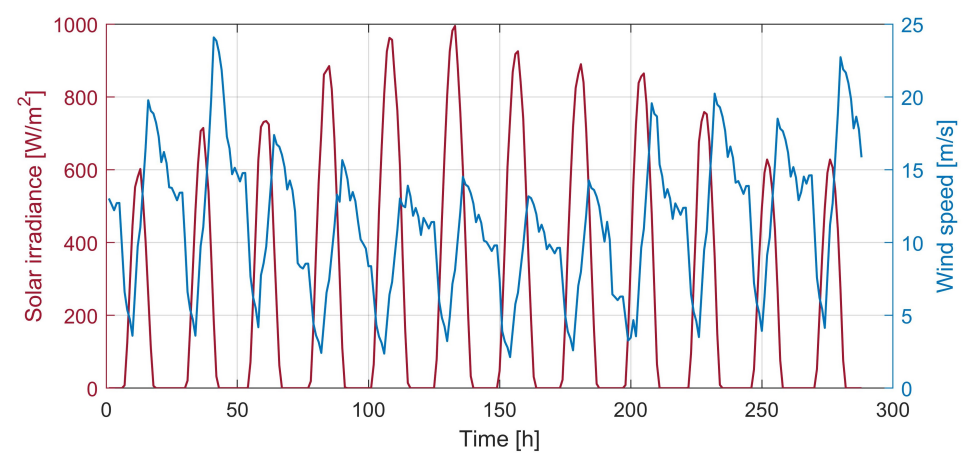

Fig. 6. Monthly averaged 24-h profiles for the solar irradiance and wind speed.

The rest of the input data in the simulation model, including the product model, specifications and economic parameters of the micro-grid components, expected reliability and lifetime parameters of the system, as well as the MFOA parameters, are as given in Sections 4 and 5. The rest of this section focuses on verifying the validity of specific novelties introduced within the context of the developed method from different perspectives as well as presenting a thorough cost-benefit analysis of the proposed micro-grid for remote communities based on the results obtained for the considered case study.

\subsection{Verification of the outperformance of the MFOA}

As stated previously, the MFOA is utilized in the proposed optimal sizing method to minimize the objective function subject to the aforementioned constraints in the operational and planning levels. In this sub-section, the performance of the MFOA is compared with the most preferred optimization algorithms in the optimal sizing studies of renewable and sustainable energy systems, i.e. the PSO and GA techniques, as well as a well-established state-of-the-art optimizer, i.e. the hybrid GA-PSO technique. The comparisons are made in terms of solution accuracy and the required iterations to converge. In order to optimize the system using the PSO, the GA, and the hybrid GA-PSO, they are embedded in the proposed optimal sizing method in a similar way to the MFOA. Accordingly, the crossover and mutation probabilities in the GA and hybrid GAPSO are set equal to 0.1 and 0.9 , respectively; while the cognitive factor, social learning factor, and inertia weight in the PSO and hybrid GA-PSO are assumed as 2, 2, and 0.7, respectively. Furthermore, in order to make a fair comparison, the population size and the maximum number of iterations for all four of these algorithms are assumed as 45 and 300 .

In order to rate the performance the considered optimizers, a statistics-directed comparison framework is employed, which comprises of four criteria: the best-case (Best), the worst-case (Worst), the mean (Mean), and the median (Median) results of the total NPC [\$] of the conceptualized MG system, obtained out of 30 independent simulation runs. Table 1 ranks the performance of the optimization algorithms under evaluation using a hybrid index $(A v g$.), which averages the pre-set criteria. The results achieved by solving the described equipment capacity planning problem using the MFOA, the PSO, the GA, and the hybrid GAPSO, utilizing the developed method, but without running the DLC-DR program, are shown in Table 1.

From Table 1, we can see that the MFOA and the PSO respectively show the best and worst performances in terms of nearing the optimal solutions within the context of this study. These statistics-based results offer compelling evidence for the superiority of the MFOA over the GA and PSO (which are the most wellknown meta-heuristic optimization algorithms in the micro-grid sizing area), and even the hybrid GA-PSO technique (which is the most recent, state-of-the-art method used in this field). Based on the best-case results, the utilization of the MFOA technique in the proposed optimal sizing method has contributed to a 
saving of $\$ 83,553(\sim 1.8 \%)$ in the target system compared with the latest meta-heuristic optimization approach proposed in the area (i.e. the hybrid GA-PSO). It has also contributed to a saving of $~ 3.0 \%$ and $\sim 7.3 \%$ in the target system compared with the GA and PSO, respectively. The superiority of the MFOA stems from its high exploitation capability. This is owing to the update procedure of moths, through which they update their positions based on the superior, feasible flames, which improves the proper exploration of the feasible design space of the problem. Furthermore, Table 2 offers a better understanding of how the total NPCs are distributed among their constituent cost components.

In addition, throughout this section, the term 'size' refers to the number for all the components except for the single-phase inverter, for which it refers to its capacity. Also, the optimal size of each component is rounded up to the next integer (because of the continuous nature of the considered optimization algorithms) and the optimal cost of the system is recalculated accordingly and then rounded to the nearest integer.

Table 1

Statistical performance comparison of the MFOA, the PSO, the GA, and the hybrid GA-PSO.

\begin{tabular}{ccccc}
\hline Metrics & GA & PSO & Hybrid GA-PSO & MFOA \\
\hline Best & $4,644,085$ & $4,862,670$ & $4,589,573$ & $4,506,020$ \\
Worst & $4,683,306$ & $4,890,443$ & $4,596,001$ & $4,517,823$ \\
Mean & $4,649,072$ & $4,860,802$ & $4,590,339$ & $4,509,715$ \\
Median & $4,644,085$ & $4,862,670$ & $4,589,573$ & $4,506,020$ \\
Avg. & $4,655,137$ & $4,869,146$ & $4,591,372$ & $4,509,895$ \\
Rank & 3 & 4 & 2 & 1 \\
\hline
\end{tabular}

Table 2

Breakdown of the best total NPCs obtained by the optimization algorithms out of 30 trials.

\begin{tabular}{ccccccc}
\hline $\begin{array}{c}\text { Optimization } \\
\text { algorithm }\end{array}$ & PV panels & WTs & $\begin{array}{c}\text { Battery } \\
\text { packs }\end{array}$ & $\begin{array}{c}\text { Inverter } \\
{[\mathrm{kW}]}\end{array}$ & EVSE & $\begin{array}{c}\text { Total NPC } \\
{[\$]}\end{array}$ \\
\hline MFOA & 687 & 45 & 58 & 339 & 6 & $4,506,020$ \\
Hybrid GA-PSO & 693 & 47 & 64 & 341 & 7 & $4,589,573$ \\
GA & 710 & 48 & 84 & 348 & 7 & $4,644,085$ \\
PSO & 772 & 52 & 91 & 377 & 9 & $4,862,670$ \\
\hline
\end{tabular}

Moreover, the minimized total NPC of the micro-grid system calculated by the aforementioned optimization algorithms over the course of iterations is shown in Fig. 7, which is plotted for the best-case performance of the optimizers. As can be seen in Fig. 7, the MFOA and GA require approximately the same number of iterations to converge, whereas the hybrid GA-PSO terminates much later. Additionally, the low performance of the PSO may be, to some extent, attributed to its early convergence, which leads to premature results. Overall, it can be stated that not only the MFOA is superior to the investigated algorithms in finding the global optima, but also its convergence speed is fast enough. 


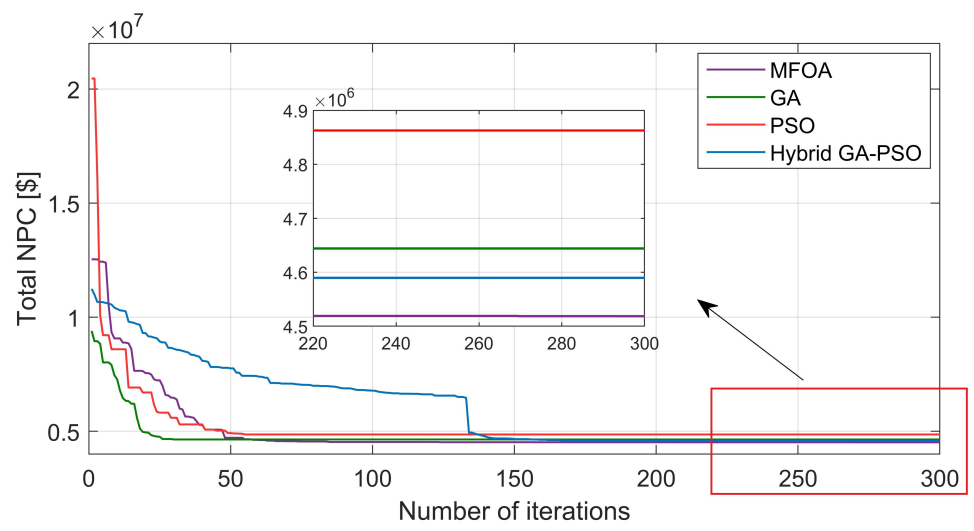

Fig. 7. Total NPC of the micro-grid in terms of iterations.

\subsection{Verification of the data compression property of the method}

As mentioned before, a data compression-based model reduction technique is used in the proposed optimal sizing method to reduce the CPU time required for simulations to preserve the computational tractability. In this sub-section, the validity of the model reduction technique is verified through a comparative analysis of the obtained results in the two cases of with and without implementing the model reduction technique in terms of solution accuracy and computational cost within the context of the proposed optimal sizing method.

In this regard, the hourly climatic and load demand data over the course of a year are fed into the simulation program in the case of not implementing the model reduction technique, whereas this data is reduced according to the procedure explained in sub-section 5.1 in the case of model reduction implementation. Accordingly, the operational time frame of the method is set as 288 and 8760 hours in the two cases of with and without implementing the model reduction technique, respectively and the micro-grid's operational performance is evaluated in the corresponding time frame in every iteration cycle. The results obtained by solving the considered equipment capacity planning problem in the two cases mentioned above (and with implementing the DSM property of the method) are shown in Table 3. The results reported in Table 3 represent the best-case results obtained after 30 runs using the MFOA. According to the table, the inclusion of the proposed model reduction technique into the method results in a remarkable reduction of the CPU usage time from around $384 \mathrm{~h}$ down to $13 \mathrm{~h}$, without compromising the optimality of the solution too much (less than $2 \%$ increment in the total NPC).

Table 3

Optimal solution of the problem with and without implementing the model reduction.

\begin{tabular}{cccccccc}
\hline Case & PV panels & WTs & $\begin{array}{c}\text { Battery } \\
\text { packs }\end{array}$ & $\begin{array}{c}\text { Inverter } \\
{[\mathrm{kW}]}\end{array}$ & EVSE & $\begin{array}{c}\text { Total NPC } \\
{[\$]}\end{array}$ & $\begin{array}{c}\text { CPU usage time } \\
{[\mathrm{h}]}\end{array}$ \\
\hline $\begin{array}{c}\text { With model } \\
\text { reduction }\end{array}$ & 687 & 45 & 58 & 339 & 6 & $4,506,020$ & 13 \\
$\begin{array}{c}\text { Without model } \\
\text { reduction }\end{array}$ & 669 & 44 & 55 & 334 & 6 & $4,424,830$ & 384 \\
\hline
\end{tabular}

Owing to the fact that micro-grids are typically designed for a useful life of 20-25 years, reducing the CPU usage time in the above-mentioned range is not valuable in itself, but it sets the scene for the incorporation of some other important and time-consuming aspects, such as uncertainty analysis using Monte Carlo simulations, energy management strategy optimization, stability analysis, and so forth, into the proposed optimal sizing method, which could otherwise lead to prohibitive CPU usage times. 


\subsection{Verification of the load shifting property of the method}

In order to implement the considered DLC-DR program, it is assumed that following a survey on the preferences of the end-users of electricity for the considered case study, $20 \%$ of the total load can be deferred by up to 4 hours without compromising the consumers' comfort level too much. The monthly averaged 24-h profile for the total electrical load on the micro-grid in the two cases of with and without demand response deployment is shown in Fig. 8. It can be seen from the figure that running the DLC-DR program has contributed to flattening the load curve by decreasing the peak load from $632.2148 \mathrm{~kW}$ to $577.0847 \mathrm{~kW}(\sim 9 \%$ peak load reduction) and improving the load factor (that is defined as the ratio of the average amount of the electrical load to the peak load) from 0.4250 to $0.4656(\sim 10 \%$ load factor enhancement). According to the load shifting nature of the DR program, the average amount of the total load over the operational time frame is the same for both the considered scenarios.

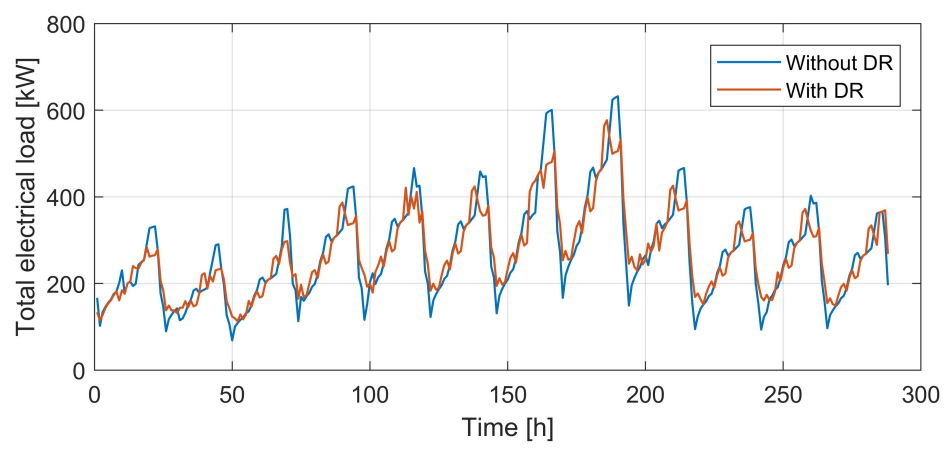

Fig. 8. Impact of employing the DR program on the load curve.

Table 4 reports the optimum results achieved in the two cases; with and without incorporating the considered DR program into the proposed optimal sizing method. These results reflect the best-case results obtained after 30 trials using the MFOA. It can be observed from the table that the application of the DR program has contributed to enhancing the micro-grid system's operational performance, which has led to a substantial decrease in the sizes of the WTs, the inverter, and the EVSE, as well as a slight increase in the number of battery packs, which, in turn, has reduced the total NPC of the MG network by $7.2 \%$. Moreover, we observe from Table 4 that the size of the PV generation is the same for both the cases. This indicates that according to the load profile and costs associated with the generation and storage technologies used within the micro-grid, supplying the loads on the micro-grid using the PV panels is cost-effective only to a certain extent, after which the loads will be supplied using the WTs and/or battery packs.

Table 4

Optimal solution of the problem with and without DR deployment.

\begin{tabular}{ccccccc}
\hline Case & PV panels & WTs & $\begin{array}{c}\text { Battery } \\
\text { packs }\end{array}$ & $\begin{array}{c}\text { Inverter } \\
{[\mathrm{kW}]}\end{array}$ & EVSE & $\begin{array}{c}\text { Total NPC } \\
{[\$]}\end{array}$ \\
\hline With DR & 687 & 45 & 58 & 339 & 6 & $4,506,020$ \\
Without DR & 687 & 56 & 47 & 352 & 7 & $4,857,334$ \\
\hline
\end{tabular}

Moreover, in order to investigate the effects of implementing the proposed DLC-DR program on the operation of the considered off-grid micro-grid, the system is operated using the obtained sizes for the components under the DR deployment (that are shown in Table 4) based on the energy management strategy used in the optimal sizing procedure in a monthly averaged daily basis (in compliance with the model reduction technique utilized in the proposed optimal sizing method) and the monthly averaged 24-h profile for the SOC of the battery bank in the two cases of with and without implementing the DR program is obtained as shown in Fig. 9. As can be seen in the figure, the implementation of the DR program increases the number of discharge/charge cycles of the battery packs. As the batteries are not appropriate for 
providing long-term energy storage solutions, the increased number of cycles increases the probability that simulations reflect real-world practice by not letting the energy be stored in the battery bank for a long time, while it is still well below the rate that negatively affects the lifetime of batteries. Note that the operational timeframe presented in Fig. 9 represents a scaled-down model of the annual operation of the micro-grid system. It should be noted that this phenomenon has not occurred accidentally and is, in fact, due to the smoothened load curve and shaved peak load, which make it possible to reduce the number of expensive WTs and benefit more from the potentials of the more cost-effective batteries by managing their charging process. This better utilization of the system components itself reduces the dissipated power by the dump load.

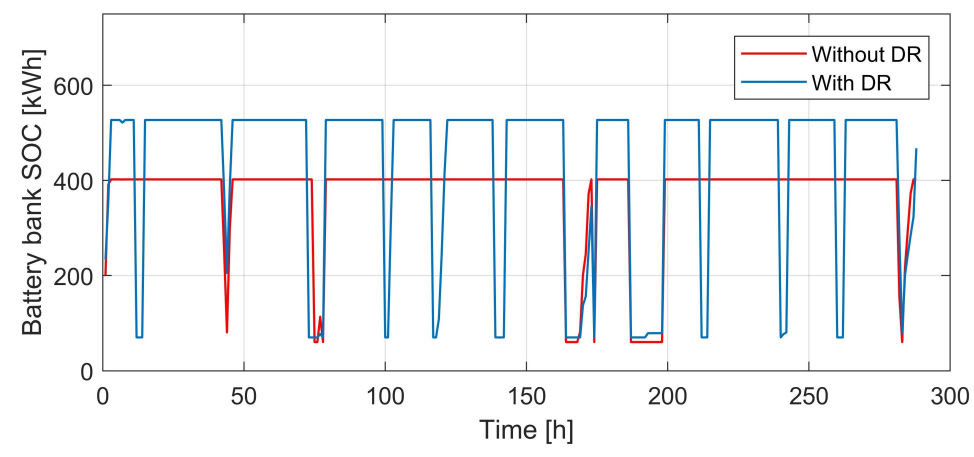

Fig. 9. Impact of DR deployment on the operation of the battery packs.

\subsection{Inverse sensitivity analysis}

As stated previously, the micro-grid designer sets the operating characteristics and actions of the considered DLC-DR program by specifying its time window and share of the deferrable loads following a survey on the preferences of the end-users for load shifting. In order to further investigate the benefits of employing the proposed DR program in the planning phase of the stand-alone micro-grids, a sensitivity analysis is carried out, which evaluates the impact of the variation of the operating characteristics of the DR program on the total NPC of the micro-grid system. In this regard, the time window of the DR program is varied from 1 to 8 hours on an hourly basis, while the amount of deferrable loads participating in the program is varied from 10 to 30 percent within 5 percent intervals. Given that the ultimate aim of such analysis is to identify the best values for the input parameters of the DR program, it is more accurate to be called an "inverse sensitivity analysis". The proposed optimal sizing method is then applied to each combination of the aforementioned variables to find the optimal total NPC of the system. The effects of changes in the operating characteristics of the proposed DR program on the optimal total NPC of the micro-grid are shown in Fig. 10. According to the results obtained by the inverse sensitivity analysis, it can be concluded that increasing the share of deferrable loads and/or time window of the DR program, decreases the total NPC of the system. The reason behind this lies in the fact that both of the above-mentioned operating characteristics of the DR program increase the flexibility of demand. Furthermore, the inverse sensitivity analysis reveals that both of the above-mentioned variables can play a key role in reducing the whole-life cost of the system. In addition, as can be seen in Fig. 10, increasing the time window of the DR program from 3 to 4 hours has the most significant effect on the life-cycle cost of the system, compared with other time window increments. Also, from the $5^{\text {th }}$ hour onwards, the rate of changes occurring in the total cost of the system is relatively low. Similarly, increasing the share of deferrable loads from 10 to 20 percent has a high impact on the total cost reduction, while it loses its importance afterwards. This analysis highlights that increasing the values of the operating characteristics of the DR program from the corresponding ranges mentioned above is not very beneficial for the considered case study and are not justifiable options even if the customers can tolerate them. This would appear to indicate that there are semi-saturation points for the operating characteristics of the proposed DR program. 


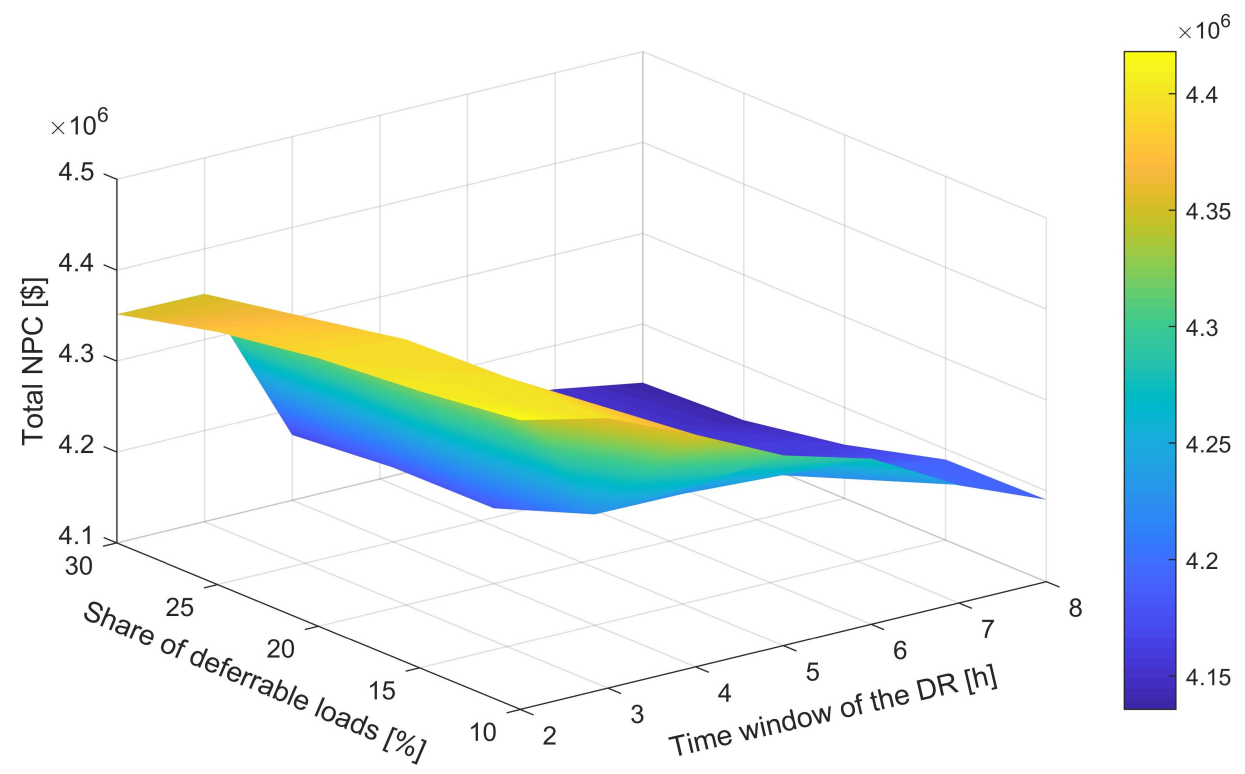

Fig. 10. Sensitivity of the total NPC to the operating characteristics of the DR program.

\subsection{Breakdown of the total NPC of the micro-grid}

A breakdown of the total NPC of the system for the best combination of the sizes of its components calculated using the developed method (which implements the load shifting strategy, uses model reduction technique, and applies the MFOA (reporting the best results obtained after 30 runs)) for the considered case study site is detailed in Fig. 11. The contribution of the NPC of the wind power generation system accounts for approximately $61 \%$ of the total NPC of the micro-grid, of which the capital cost occupies about $65 \%$, which is the dominant cost factor for installing the proposed micro-grid system. The NPC of the other renewable power generation technology utilized in the micro-grid, i.e. PV panels, accounts for nearly $20 \%$ of the total NPC. The NPC of the single-phase inverter accounts for approximately $10 \%$ of the total NPC of the micro-grid, followed by the NPC of the battery bank, which takes up nearly $8 \%$, while the least cost component is the EVSE, whose NPC contributes at less than $1 \%$ of the total NPC. It is interesting to note that unlike most of the stand-alone micro-grids, in which the cost of the storage sub-system is dominant [70], the battery bank comes second last among the micro-grid components in terms of cost in this project. This is due to the highly complementary time behaviour of the solar and wind resources at the considered site.

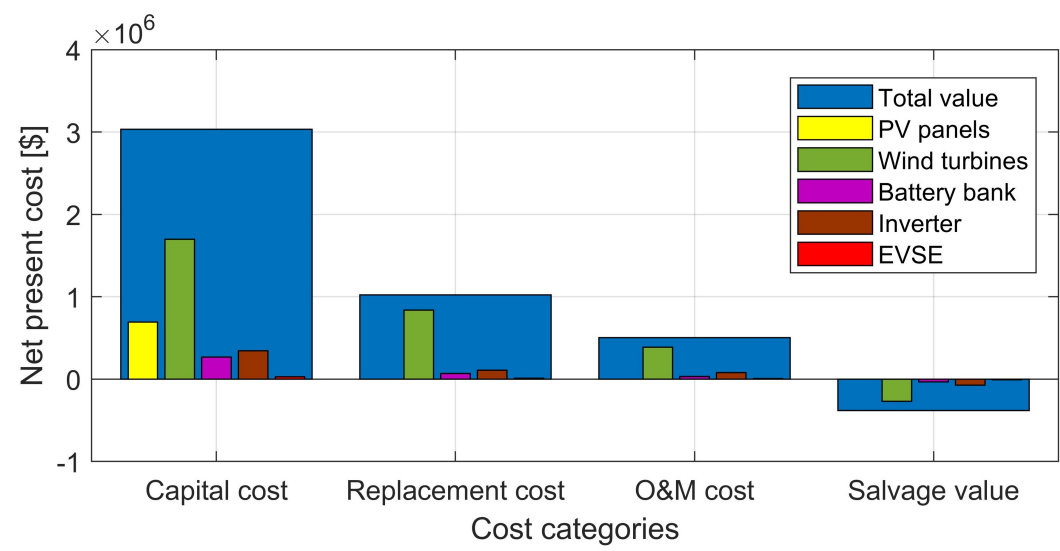

Fig. 11. Cash flow breakdown by components and cost categories. 
Moreover, the levelized cost of energy (LCOE) of the considered micro-grid is calculated using the method suggested by Lotfi and Khodaei [71]. The LCOE of the micro-grid system is found as $\$ 0.15 / \mathrm{kWh}$. The electricity price is much lower in Iran than that in the vast majority of the world due to the government's subsidies (i.e. $\$ 0.01 / \mathrm{kWh}$ ) and the electricity is mainly generated by fossil fuel-fired power plants (around $94 \%$ of the total electricity generation). However, the actual price (full cost) of electricity without considering the fossil-fuel subsidies is $\$ 0.21 / \mathrm{kWh}$ [72]. Therefore, the calculated LCOE in this project is comparable to, and competitive with, conventional fossil fuel-fired power plants. This makes the project economically feasible for installation on Hengam Island, especially since, currently, the required power demand of the island is being supplied through submarine power cables with lengths of $45 \mathrm{~km}$ that transmit the power from Qeshm Island, which is connected to the Iran National Grid by overhead transmission lines. Moreover, due to the fact that the service lives of those submarine power cables are nearly over (causing frequent power outages), it is also expected that the implementation of this project will improve the reliability of power supply in the considered case study site. Additionally, the proposed micro-grid has modelled the EV charging loads, providing a solution for the integration of an EV fleet into the system to meet the transportation needs without requiring fossil fuel imports, which effectively contributes to the island's sustainable development objectives.

\subsection{Energy balance analysis}

The energy flow of the system based on running the program simulating the operational strategy of the micro-grid over the reduced operational time frame (i.e. 288 hours), using the optimum sizes obtained by the proposed optimal equipment capacity planning method, is summarized in Fig. 12. Such analysis can be applied to other operational horizons (e.g. one year, same as the one that carried out in sub-section 6.3) by simply adjusting and adapting the input variables to the model. One other point that should not be neglected is the size of the equipment should be selected based on the optimal solutions calculated using the proposed optimal sizing method for the same operational time span, when conducting such an analysis. This mechanism prevents the occurrence of mismatches between energy supply and demand within the microgrid. But, as it has been demonstrated in sub-section 6.3, reducing the one-year hourly values of the model input variables is reasonably tolerable up to 288 hours, i.e. the monthly averaged 24 -h profiles for the variables. This means that the percentage values obtained for every energy generation/consumption component of the system in the $288 \mathrm{~h}$ energy balance analysis, shown in Fig. 12, reflect the corresponding values for a yearly energy balance analysis with only a minor loss in accuracy.

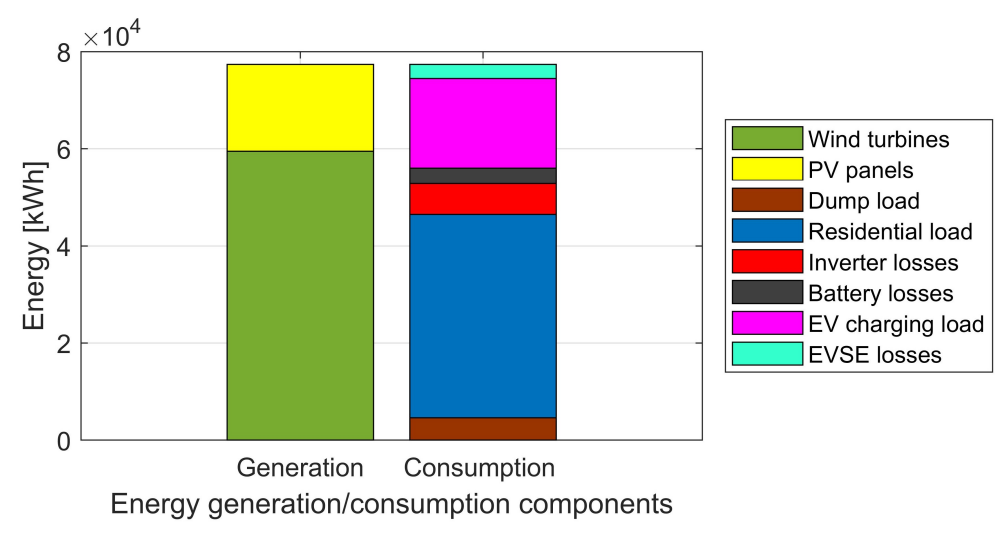

Fig. 12. Balance between the energy generation and consumption within the micro-grid.

As illustrated in Fig. 12, almost 77\% of the energy generated within the micro-grid is contributed by WTs and approximately $23 \%$ by PV panels. The dominant energy consumption component is that of residential loads that accounts for nearly $54 \%$ of the total energy consumption within the micro-grid, which is met with an ELF reliability index of 0.01. The other energy demand component from the micro-grid customers, i.e. the EV charging load, occupies about $24 \%$ of the whole micro-grid energy consumption, which is satisfied with an ELF reliability index of 0.02 , followed by the total system losses, which take up nearly 
$22 \%$ of the total energy consumption. The total system losses consist of the single-phase inverter losses, the energy circulated in the DC dump load as spilled energy, battery bank losses, and EVSE losses, which take up approximately $37 \%, 27 \%, 18 \%$, and $17 \%$, respectively. The reason for such a low amount of energy dissipated through dump load is due to the complementary characteristics of the solar and wind resources in the studied region, as well as implementing a DR program to flatten the load profile in the proposed optimal sizing method.

\subsection{Validation of the viability of the project}

In order to validate the economic sustainability of the project under discussion, a detailed assessment of the expected costs and revenues based upon the following three metrics for measuring risk in investments is carried out with: (1) the discounted payback period (DPP), (2) the profitability index (PI), and the (3) internal rate of return (IRR).

The DPP metric, which determines the break-even point, after which an investment project achieves profitability with regards to the real discount rate (i.e. the real interest rate) can be calculated as follows [73]:

$$
\sum_{t=0}^{D P P} S(1+i r)^{-t}-N P C_{\text {total }}=0,
$$

where $S$ is the annual revenue generated by selling electricity to the customers of the micro-grid. In this analysis, we have assumed a fixed-rate plan for selling electricity with a flat price of $\$ 0.21 / \mathrm{kWh}$, which is in compliance with the existing actual cost of electricity generation without fossil-fuel subsidies in Iran.

The PI is measured as the ratio of the value of the total investments made for a business/strategic plan over its life-cycle to its capital expenditures, which can be calculated by the following equation [73]:

$$
P I=100 \times \frac{\sum_{t=0}^{R} S(1+i r)^{-t}-N P C_{t o t a l}}{\operatorname{Cap}_{T}},
$$

where $R$ represents the conceptualized micro-grid's service life and $\operatorname{Cap}_{T}$ denotes the total capital expenditures on the implementation of the micro-grid in the baseline year.

The IRR is expressed as a discount rate, by which the total NPC of a capitalization scheme equals zero; meaning that, the investment breaks even before it creates any revenues. The IRR metric, whose larger value signifies higher viability of the plan to invest, can be calculated by Eq. (33) [73].

$$
\sum_{t=0}^{R} \frac{C F(t)}{(1+i r)^{t}}-I V=0
$$

where $C F(t)$ denotes the net capital inflow in the $t$-th investment year, $I V$ represents the total initial investment costs, and ir (i.e. the real interest rate in the NPC concept), identifies the IRR.

Table 5 reports the determined DPP, PI, and IRR of the micro-grid investment program, whose financial viability is under assessment. The table provides strong evidence that the project at hand is not only economically worthwhile to renewable electrify a population of 615 residing on Hengam Island, but also can be viewed as a relatively risk-free, high-reward financing opportunity, which ensures its investors a consistent profit stream.

Table 5

Financial viability evaluation of the MG development plan under analysis.

\begin{tabular}{ccc}
\hline DPP [years] & PI [\%] & IRR [\%] \\
\hline 10.53 & 2.09 & 11.28 \\
\hline
\end{tabular}




\section{Conclusions and future work}

This paper has devised an optimal sizing methodology for stand-alone micro-grids, which takes into account the coordination of EVs charging and deferment of residential loads based on compressed meteorological and load demand data, whilst attempting to highlight the effectiveness of the MFOA in solving the considered problem. We have obtained satisfactory results demonstrating the effectiveness of the abovementioned innovative, cutting-edge strategies in contributing toward reducing the isolated micro-grids' lifetime cost, as well as the computational complexity of the problem-solving.

The results of this study support the idea that implementing the DLC-DR programs based on the load deferment potentials of the residential and EV charging loads that flatten the load profile by shaving the peak demands, while optimally sizing the components of the grid-independent micro-grids, reduces their overall cost according to the reduced sizes for some of the components. In addition, an inverse sensitivity analysis has evaluated how the changes in operating characteristics of the DR program (i.e. the share of deferrable loads and the time window in which they can be scheduled) influence the life-cycle cost of the considered micro-grid test-case system and what their best values are. The analysis highlights that there are semi-saturation points for the amounts of operating plans used in the DR program in the context of off-grid renewable power supply. Energy providers can benefit from these findings and make appropriate decisions regarding the penetration of time-shiftable loads, for creating load flexibility and enabling a peak load shaving capability for whole-life cost reduction purposes in the planning phase of the isolated micro-grids.

Furthermore, since the optimal sizing problem of renewable and sustainable energy systems is a non-convex and non-linear combinational optimization problem, making it not amenable to conventional mathematical optimization approaches, the performances of the most preferred meta-heuristic optimization algorithms in this field, i.e. the GA and PSO, were compared with those of the two state-of-the-art meta-heuristic approaches, namely the hybrid GA-PSO and MFOA, in terms of convergence speed and optimality of the solution obtained. The evidence from this study intimates that the MFOA outperforms the other metaheuristics mentioned above in terms of better quality solutions (by a considerable margin, from an optimization perspective), whilst having an appropriate convergence speed.

Moreover, the findings of this study indicate that the efficient implementation of a model reduction strategy, whereby the climatic and load demand data could be significantly reduced, alleviates the required CPU usage time for simulating the proposed optimal sizing method, whilst retaining the solution accuracy in a satisfactory level. Such a model reduction, in fact, paves the way for the incorporation of other timeconsuming analyses into the proposed method without losing the computational tractability. In particular, we have confirmed that compressing the one year of hourly data ( 8,760 data points per data stream) to monthly-averaged daily data (288 data points per data stream) substantially reduces the CPU usage time without sacrificing the solution accuracy too much.

This study considered a conceptual stand-alone micro-grid on Hengam Island to verify the validity of the proposed optimal sizing method. However, the distributed energy technologies used in the proposed microgrid can also be updated based on the renewable energy potential of other sites, as well as the so-called production-related full cost of DERs as a reflection of local industries and policies. Besides, the method devised in this study is not essentially targeted on and constrained to residential and EV parking lot customers. Indeed, the proposed method can be usefully applied to other islanded micro-grid development projects including different load profiles (such as commercial, industrial, and/or agricultural loads), by simply adjusting the corresponding variables and pursuing the same procedure for the optimal sizing of the components.

In order to make the simulation results a more accurate representative of the real-world scenarios, and make the proposed micro-grid smarter, we see two key areas for future work. The first is addressing the uncertainties inherent in various variables (e.g. energy demand growth, renewable power supply, system losses, inflation rate, etc.) of the micro-grid network using uncertainty analysis techniques, such as Monte Carlo simulations, chance-constrained programming, stochastic programming, robust programming, and so 
forth. The second key area is the development of more sophisticated energy management strategies (e.g. distributed optimization, stability-constrained optimal power flow, energy management by fuzzy logic controllers, etc.) within the proposed optimal sizing method that operate the micro-grids in an economically efficient and intelligent manner.

\section{References}

[1] A. S. Oyewo, A. Aghahosseini, D. Bogdanov, and C. Breyer, "Pathways to a fully sustainable electricity supply for Nigeria in the mid-term future," Energy Convers. Manag., vol. 178, pp. 44-64, 2018.

[2] M. Child, A. Nordling, and C. Breyer, "Scenarios for a sustainable energy system in the Åland Islands in 2030," Energy Convers. Manag., vol. 137, pp. 49-60, 2017.

[3] T. Bulavskaya and F. Reynès, "Job creation and economic impact of renewable energy in the Netherlands," Renew. Energy, vol. 119, pp. 528-538, 2018.

[4] Z. Abdin and W. Mérida, "Hybrid energy systems for off-grid power supply and hydrogen production based on renewable energy: A techno-economic analysis," Energy Convers. Manag., vol. 196, pp. 1068-1079, 2019.

[5] S. M. Moghaddas-Tafreshi, S. Mohseni, M. E. Karami, and S. Kelly "Optimal energy management of a gridconnected multiple energy carrier micro-grid," Appl. Therm. Eng., vol. 152, pp. 796-806, 2019.

[6] A. García-Olivares, J. Solé, and O. Osychenko, "Transportation in a 100\% renewable energy system," Energy Convers. Manag., vol. 158, pp. 266-285, 2018.

[7] R. Álvarez Fernández, "A more realistic approach to electric vehicle contribution to greenhouse gas emissions in the city," J. Clean. Prod., vol. 172, pp. 949-959, 2018.

[8] S. M. Moghaddas-Tafreshi, M. Jafari, S. Mohseni, and S. Kelly, "Optimal operation of an energy hub considering the uncertainty associated with the power consumption of plug-in hybrid electric vehicles using information gap decision theory," Int. J. Electr. Power Energy Syst., vol. 112, pp. 92-108, 2019.

[9] M. F. Hossain, S. Hossain, and M. J. Uddin, "Renewable energy: Prospects and trends in Bangladesh," Renew. Sustain. Energy Rev., vol. 70, pp. 44-49, 2017.

[10] D. T. Ton and M. A. Smith, "The U.S. Department of Energy's Microgrid Initiative," Electr. J., vol. 25, no. 8, pp. 84-94, 2012.

[11] S. V. Oprea, A. Bâra, A. I. Uţă, A. Pîrjan, and G. Căruţaşu, "Analyses of distributed generation and storage effect on the electricity consumption curve in the smart grid context," Sustain., vol. 10, no. 7, 2018.

[12] S. Kahrobaee and S. Asgarpoor, "The effect of demand side management on reliability of automated distribution systems," in Proceedings of the 2013 1st IEEE Conf. Technol. Sustain. (SusTech), Portland, OR, USA, 1-2 Aug. 2013, pp. 179-183.

[13] N. G. Paterakis, O. Erdinç, and J. P. S. Catalão, "An overview of Demand Response: Key-elements and international experience,” Renew. Sustain. Energy Rev., vol. 69, pp. 871-891, 2017.

[14] J. Aghaie and M.-I. Alizadeh, "Demand response in smart electricity grids equipped with renewable energy sources: A review," Renew. Sustain. Energy Rev., vol. 18, pp. 64-72, 2013.

[15] N. A. Sinitsyn, S. Kundu, and S. Backhaus, "Safe protocols for generating power pulses with heterogeneous populations of thermostatically controlled loads ," Energy Convers. Manag., vol. 67, pp. 297-308, 2013.

[16] A. Maleki and F. Pourfayaz, "Optimal sizing of autonomous hybrid photovoltaic/wind/battery power system with LPSP technology by using evolutionary algorithms," Sol. Energy, vol. 115, pp. 471-483, 2015.

[17] J. Jung and M. Villaran, "Optimal planning and design of hybrid renewable energy systems for microgrids," Renew. Sustain. Energy Rev., vol. 75, pp. 180-191, 2017.

[18] G. Mavrotas, K. Florios, and D. Vlachou, "Energy planning of a hospital using Mathematical Programming and Monte Carlo simulation for dealing with uncertainty in the economic parameters," Energy Convers. Manag., vol. 51, no. 4, pp. 722-731, 2010.

[19] A. Maleki, H. Hafeznia, M. A. Rosen, and F. Pourfayaz, "Optimization of a grid-connected hybrid solarwind-hydrogen CHP system for residential applications by efficient metaheuristic approaches," Appl. Therm. Eng., vol. 123, pp. 1263-1277, 2017. 
[20] S. M. Moghaddas-Tafreshi, H. A. Zamani, and S. M. Hakimi, "Optimal sizing of distributed resources in micro grid with loss of power supply probability technology by using breeding particle swarm optimization," J. Renew. Sustain. Energy, vol. 3, no. 4, 2011.

[21] M. Kefayat, A. Lashkar Ara, and S. A. Nabavi Niaki, "A hybrid of ant colony optimization and artificial bee colony algorithm for probabilistic optimal placement and sizing of distributed energy resources," Energy Convers. Manag., vol. 92, pp. 149-161, 2015.

[22] M. M. Aman, G. B. Jasmon, A. H. A. Bakar, and H. Mokhlis, “A new approach for optimum simultaneous multi-DG distributed generation Units placement and sizing based on maximization of system loadability using HPSO (hybrid particle swarm optimization) algorithm," Energy, vol. 66, pp. 202-215, 2014.

[23] E. S. Ali, S. M. Abd Elazim, and A. Y. Abdelaziz, "Ant Lion Optimization Algorithm for optimal location and sizing of renewable distributed generations," Renew. Energy, vol. 101, pp. 1311-1324, 2017.

[24] M. R. Mozafar, M. H. Moradi, and M. H. Amini, "A simultaneous approach for optimal allocation of renewable energy sources and electric vehicle charging stations in smart grids based on improved GA-PSO algorithm," Sustain. Cities Soc., vol. 32, pp. 627-637, 2017.

[25] N. Ghorbani, A. Kasaeian, A. Toopshekan, L. Bahrami, and A. Maghami, "Optimizing a Hybrid Wind-PVBattery System Using GA-PSO and MOPSO for Reducing Cost and Increasing Reliability,” Energy, vol. 154, pp. 581-591, 2017.

[26] A. Maleki and F. Pourfayaz, "Sizing of stand-alone photovoltaic / wind / diesel system with battery and fuel cell storage devices by harmony search algorithm," J. Energy Storage, vol. 2, pp. 30-42, 2015.

[27] W. Dong, Y. Li, and J. Xiang, "Optimal sizing of a stand-alone hybrid power system based on battery/hydrogen with an improved ant colony optimization," Energies, vol. 9, no. 10, 2016.

[28] A. Kaabeche, S. Diaf, and R. Ibtiouen, "Firefly-inspired algorithm for optimal sizing of renewable hybrid system considering reliability criteria," Sol. Energy, vol. 155, pp. 727-738, 2017.

[29] C. Shang, D. Srinivasan, and T. Reindl, "An improved particle swarm optimisation algorithm applied to battery sizing for stand-alone hybrid power systems,” Int. J. Electr. Power Energy Syst., vol. 74, pp. 104 117, 2016.

[30] P. Nagapurkar and J. D. Smith, "Techno-economic optimization and environmental Life Cycle Assessment (LCA) of microgrids located in the US using genetic algorithm," Energy Convers. Manag., vol. 181, pp. 272-292, 2019.

[31] Y. Sawle, S. C. Gupta, and A. K. Bohre, "Optimal sizing of standalone PV/Wind/Biomass hybrid energy system using GA and PSO optimization technique,” Energy Procedia, vol. 117, pp. 690-698, 2017.

[32] D. H. Wolpert and W. G. Macready, "No free lunch theorems for optimization," IEEE Trans. Evol. Comput., vol. 1, no. 1, pp. 67-82, 1997.

[33] C. Gamarra and J. M. Guerrero, "Computational optimization techniques applied to microgrids planning: A review," Renew. Sustain. Energy Rev., vol. 48, pp. 413-424, 2015.

[34] M. D. A. Al-falahi, S. D. G. Jayasinghe, and H. Enshaei, "A review on recent size optimization methodologies for standalone solar and wind hybrid renewable energy system," Energy Convers. Manag., vol. 143, pp. 252-274, 2017.

[35] A. Chauhan and R. P. Saini, “A review on Integrated Renewable Energy System based power generation for stand-alone applications: Configurations, storage options, sizing methodologies and control," Renew. Sustain. Energy Rev., vol. 38, pp. 99-120, 2014.

[36] R. Ayop, N. M. Isa, and C. W. Tan, "Components sizing of photovoltaic stand-alone system based on loss of power supply probability,” Renew. Sustain. Energy Rev., vol. 81, pp. 2731-2743, 2018.

[37] T. Tezer, R. Yaman, and G. Yaman, "Evaluation of approaches used for optimization of stand-alone hybrid renewable energy systems,” Renew. Sustain. Energy Rev., vol. 73, pp. 840-853, 2017.

[38] O. Erdinc, N. G. Paterakis, I. N. Pappi, A. G. Bakirtzis, and J. P. S. Catalão, "A new perspective for sizing of distributed generation and energy storage for smart households under demand response," Appl. Energy, vol. 143, pp. 26-37, 2015.

[39] S. Nojavan, M. Majidi, and N. N. Esfetanaj, "An efficient cost-reliability optimization model for optimal siting and sizing of energy storage system in a microgrid in the presence of responsible load management," 
Energy, 2017.

[40] Y. Zheng, B. M. Jenkins, K. Kornbluth, and C. Træholt, "Optimization under uncertainty of a biomassintegrated renewable energy microgrid with energy storage," Renew. Energy, vol. 123, pp. 204-217, 2018.

[41] Y. Zheng, B. M. Jenkins, K. Kornbluth, A. Kendall, and C. Træholt, "Optimization of a biomass-integrated renewable energy microgrid with demand side management under uncertainty," Appl. Energy, vol. 230, pp. 836-844, 2018.

[42] V. Amir, S. Jadid, and M. Ehsan, "Optimal Planning of a Multi-Carrier Microgrid ( MCMG ) Considering Demand-Side Management," Int. J. Renew. Energy Res., vol. 8, no. 1, 2018.

[43] S. M. Hakimi and S. M. Moghaddas-Tafreshi, "Optimal planning of a smart microgrid including demand response and intermittent renewable energy resources," IEEE Trans. Smart Grid, vol. 5, no. 6, pp. 28892900, 2014.

[44] S. Pazouki and M. R. Haghifam, "Optimal planning and scheduling of energy hub in presence of wind, storage and demand response under uncertainty," Int. J. Electr. Power Energy Syst., vol. 80, pp. 219-239, 2016.

[45] S. Kahrobaee, S. Asgarpoor, and W. Qiao, "Optimum sizing of distributed generation and storage capacity in smart households,” IEEE Trans. Smart Grid, vol. 4, no. 4, pp. 1791-1801, 2013.

[46] T. Liu, D. Zhang, S. Wang, and T. Wu, "Standardized modelling and economic optimization of multi-carrier energy systems considering energy storage and demand response," Energy Convers. Manag., vol. 182, pp. 126-142, 2019.

[47] A. Chauhan and R. P. Saini, "Size optimization and demand response of a stand-alone integrated renewable energy system," Energy, vol. 124, pp. 59-73, 2017.

[48] M. H. Amrollahi and S. M. T. Bathaee, "Techno-economic optimization of hybrid photovoltaic/wind generation together with energy storage system in a stand-alone micro-grid subjected to demand response," Appl. Energy, vol. 202, pp. 66-77, 2017.

[49] L. Zhu, Z. Yan, W. J. Lee, X. Yang, Y. Fu, and W. Cao, "Direct Load Control in Microgrids to Enhance the Performance of Integrated Resources Planning,” IEEE Trans. Ind. Appl., vol. 51, no. 5, pp. 3553-3560, 2015.

[50] X. Liu, H. Chen, B. Huang, and Y. Tao, "Optimal Sizing for Wind / PV / Battery System Using Fuzzy cMeans Clustering with Self-Adapted Cluster Number," vol. 2017, 2017.

[51] H. HassanzadehFard, S. M. Moghaddas-Tafreshi, and S. M. Hakimi, "Effect of energy storage systems on optimal sizing of islanded micro-grid considering interruptible loads," in Proceedings of the $20113 \mathrm{rd}$ Int. Youth Conf. Energ., Leiria, Portugal, 7-9 Jul. 2011, pp. 1-7.

[52] S. M. Hakimi and S. M. Moghaddas-Tafreshi, "Optimal sizing of a stand-alone hybrid power system via particle swarm optimization for Kahnouj area in south-east of Iran," Renew. Energy, vol. 34, no. 7, pp. 1855-1862, 2009.

[53] M. Smaoui, A. Abdelkafi, and L. Krichen, "Sizing of a stand-alone hybrid system supplying a desalination unit," STA 2014 - 15th Int. Conf. Sci. Tech. Autom. Control Comput. Eng., vol. 120, pp. 820-824, 2014.

[54] A. C. Duman and Ö. Güler, "Techno-economic analysis of off-grid PV/wind/fuel cell hybrid system combinations with a comparison of regularly and seasonally occupied households," Sustain. Cities Soc., vol. 42, pp. 107-126, 2018.

[55] S. M. Hakimi, S. M. M. Tafreshi, and A. Kashefi, "Unit sizing of a stand-alone hybrid power system using Particle Swarm Optimization (PSO)," in Proceedings of the 2007 IEEE International Conference on Automation and Logistics, Jinan, China, 18-21 Aug. 2007, pp. 3107-3112.

[56] S. X. Chen, H. B. Gooi, and M. Q. Wang, "Sizing of energy storage for microgrids," IEEE Trans. Smart Grid, vol. 3, no. 1, pp. 142-151, 2012.

[57] M. A. M. Ramli, H. R. E. H. Bouchekara, and A. S. Alghamdi, "Optimal sizing of PV/wind/diesel hybrid microgrid system using multi-objective self-adaptive differential evolution algorithm,” Renew. Energy, vol. 121, pp. 400-411, 2018.

[58] R. Kaiser, "Optimized battery-management system to improve storage lifetime in renewable energy systems," J. Power Sources, vol. 168, no. 1, pp. 58-65, 2007. 
[59] S. Mohseni and S. M. Moghaddas-Tafreshi, "A multi-agent system for optimal sizing of a cooperative selfsustainable multi-carrier microgrid,” Sustain. Cities Soc., vol. 38, pp. 452-465, 2018.

[60] M. Naderi, S. Bahramara, Y. Khayat, and H. Bevrani, "Optimal planning in a developing industrial microgrid with sensitive loads," Energy Reports, vol. 3, pp. 124-134, 2017.

[61] R. Billinton and R. N. Allan, Reliability evaluation of engineering systems: concepts and techniques, Second. New York: Plenum Press, 1992.

[62] R. S. Garcia and D. Weisser, "A wind-diesel system with hydrogen storage: Joint optimisation of design and dispatch," Renew. Energy, vol. 31, no. 14, pp. 2296-2320, 2006.

[63] A. P. Agalgaonkar, C. V. Dobariya, M. G. Kanabar, S. A. Khaparde, and S. V. Kulkarni "Optimal sizing of distributed generators in microgrid," in Proceedings of the 2006 IEEE Power India Conf., New Delhi, India, 10-12 Apr. 2006, pp. 901-908.

[64] S. Mirjalili, "Moth-flame optimization algorithm: A novel nature-inspired heuristic paradigm," KnowledgeBased Syst., vol. 89, pp. 228-249, 2015.

[65] S. N. Sivanandam and S. N. Deepa, Introduction to Genetic Algorithms, Springer-Verlag, Berlin, Heidelberg, 2008.

[66] J. Kennedy and R. C. Eberhart, "Particle swarm optimization," in Proceedings of the 1995 IEEE International Conference on Neural Networks, Perth, WA, Australia, 27 Nov.-1 Dec. 1995, vol. 4, pp. 1942-1948.

[67] Y. T. Kao and E. Zahara, "A hybrid genetic algorithm and particle swarm optimization for multimodal functions," Appl. Soft Comput. J., vol. 8, no. 2, pp. 849-857, 2008.

[68] X. Liang, T. T. Lie, and M. H. Haque, "A Cost-Effective EV Charging Method Designed For Residential Homes with Renewable Energy,” pp. 207-208, 2014.

[69] Y. Xiang, J. Liu, R. Li, F. Li, C. Gu, and S. Tang, "Economic planning of electric vehicle charging stations considering traffic constraints and load profile templates," Appl. Energy, vol. 178, pp. 647-659, 2016.

[70] T. Ma, H. Yang, and L. Lu, "A feasibility study of a stand-alone hybrid solar-wind-battery system for a remote island," Appl. Energy, vol. 121, pp. 149-158, 2014.

[71] H. Lotfi and A. Khodaei, "Levelized cost of energy calculations for microgrids," in Proceedings of the 2016 IEEE Power Energy Soc. Gen. Meet., Boston, MA, USA, 17-21 Jul. 2016, pp. 1-5.

[72] S. S. Korsavi, Z. S. Zomorodian, and M. Tahsildoost, "Energy and economic performance of rooftop PV panels in the hot and dry climate of Iran," J. Clean. Prod., vol. 174, pp. 1204-1214, 2018.

[73] D. L. Talavera, E. Muñoz-Cerón, J. P. Ferrer-Rodríguez, and P. J. Pérez-Higueras, "Assessment of costcompetitiveness and profitability of fixed and tracking photovoltaic systems: The case of five specific sites," Renew. Energy, vol. 134, pp. 902-913, 2019. 